\title{
The effect of the use of radiant barriers in building roofs on summer comfort conditions - A case study
}

\author{
Miguel Ferreira ${ }^{\mathrm{a}, *}$, Helena Corvacho ${ }^{\mathrm{b}}$ \\ a Fernando Pessoa University, Faculty of Science and Technology, Praça 9 de Abril n³49, Porto 4249-004, Portugal \\ ${ }^{\mathrm{b}}$ University of Porto, CONSTRUCT- LFC, Faculty of Engineering, Civil Engineering Department, Laboratory of Building Physics, Rua Dr. Roberto Frias, Porto \\ 4200-465, Portugal
}

\section{A R T I C L E I N F O}

\section{Article history:}

Received 5 November 2017

Revised 9 June 2018

Accepted 23 June 2018

Available online 7 July 2018

\section{Keywords:}

Radiant barrier

Low emissivity

Roofs

Summer thermal comfort

\begin{abstract}
A B S T R A C T
A brief analysis on radiant barriers applied in building roofs, included in a wider study, is presented. A case study which involves experimental measurements carried out in a single-family house, located in a mild climate, specifically in the North of Portugal, where radiant barriers were applied and monitored is described.

A computer program (CAPSOL) was also used to carry out a sensitivity analysis and to verify if the results pointed to conclusions similar to those of the experimental measurements.

In the experimental part of this work, which took place in the summer periods of two consecutive years, two different roofs were monitored in the same house. Values of temperature, relative humidity, solar irradiance, heat fluxes among other parameters were measured. This article presents some of the collected data.

In the numerical simulation, the comparison between the situation of the inclusion of a radiant barrier underneath the roof tiles and over the attic floor slab is presented and compared with another situation without this barrier.

In general, it was concluded from this brief analysis that the application of a radiant barrier in the roof of a building proves to be advantageous, especially in what regards the attenuation of the maximum temperatures reached at the roof attic, thus mitigating the risk of overheating.
\end{abstract}

(C) 2018 Elsevier B.V. All rights reserved.

\section{Radiant barrier systems}

Vittorino, Sato and Akutsu [1] among others present one possible definition of thermal insulation material. They report that thermal insulation of roofs was traditionally limited to the use of resistive materials which, mainly due to the large amount of air between fibers or confined in small cells, reduce heat transfer by conduction. French Standard NF P 75.01 (AFNOR cit. In [1]) defines as thermal insulation exclusively that material having a thermal resistance greater than or equal to $0.5 \mathrm{~m}^{2} . \mathrm{K} / \mathrm{W}$ and a thermal conductivity less than or equal to $0.065 \mathrm{~W} /(\mathrm{m} . \mathrm{K})$.

Later, materials promoting the reduction of heat exchanges by radiation, as it is the case of radiant barriers, were also considered. For example, in the US, several technical standards have been developed, such as ASTM C 727-01 [2], which defines rules for the installation and use of reflective insulation in building constructions, such as metallic films confronting closed air spaces. A solution like

\footnotetext{
* Corresponding author.

E-mail addresses: miguelf@ufp.edu.pt (M. Ferreira), corvacho@fe.up.pt (H. Corvacho).
}

a radiant barrier, which minimizes heat transfer by radiation, increasing the air space thermal resistance close to it, due to its low emissivity [3], is of course and by definition a thermal insulation, such as an insulation material which acts primarily by thermal resistance to heat conduction. Thus, the evaluation of insulation materials cannot be carried out solely because of their characteristics related to pure conduction.

From the above, thermal insulation materials can be grouped into two main groups: resistive ones, which act predominantly on heat transfer by conduction and low emissivity reflective ones (radiant barriers) which act mainly on the transfer of heat by radiation.

In the field of radiant barriers Al-Homoud [4] addresses metallic or metallized reflective membranes that may be aluminum films and also ceramic with special radiation control coatings which in order to work properly must confront a space filled with air, gas or vacuum and must be installed in such a way as to avoid the negative interference caused by the accumulation of dust.

The construction elements that have to be more carefully insulated to heat transfer by radiation are the roofs which in summer can cause severe effects of overheating. Therefore, in these cases a 


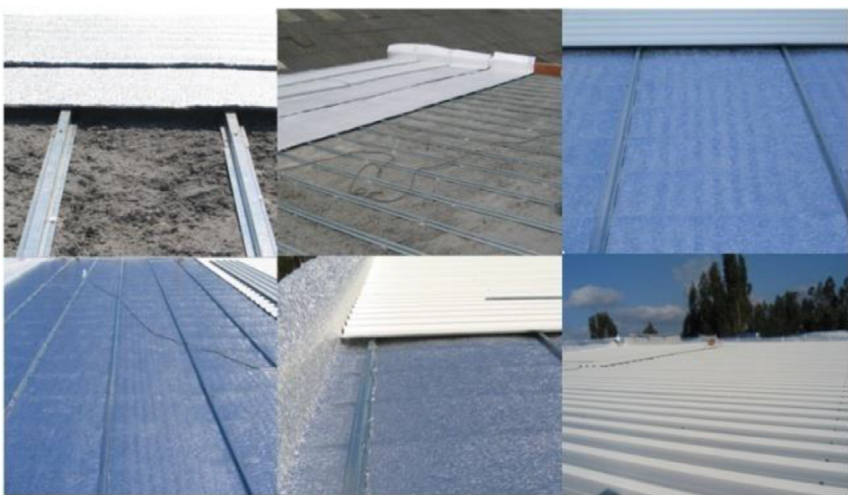

Fig. 1. Application of a radiant barrier under a metallic roof.

radiant barrier normally consisting of polished aluminum foils may be effective. Something that is extremely important to meet in the installation of these solutions is the adoption of an air gap of at least $2.5 \mathrm{~cm}$ between the reflective foil and the adjacent building element [5].

An example of an application of a radiant barrier, object of analysis in this study, is shown in Fig. 1. The aluminum coating has an emissivity of 0.06 [6]. It was applied under the metallic roof of the offices of the supplier company. Its design and monitoring was undertaken in the scope of a wider study carried out.

Another assembly scheme adapted to pitched roofs which was used in the scope of the present work, is the application of the radiant barrier over the upper storey ceiling slab (floor of the roof attic), however this application may have more obvious problems of increasing the emissivity of aluminum foils with the accumulation of dust and debris, as well as, being an electric conductive material, a particular care must be taken to avoid a possible contact with electricity cables.

With regard to the applications of aluminum in food packaging which may be reused for low-emissivity reflective thermal insulation blankets in buildings, normally aluminum foils are incorporated in a set of layers of other products. The polyethylene layer coating the aluminum foil reduces the reflectance and increases the emissivity thereof. An emissivity value of 0.29 was measured by the authors of the present paper for the inner surface of a liquid food carton.

The possible removal of the polyethylene surface films while maintaining the aluminum bonding to the carton would certainly be interesting for the application of this material in buildings in the form of blankets with high thermal radiation reflection performance.

Studies carried out in Brazil [7] concluded that after nine months of direct sun exposure, but without contact with rain, and due to aging caused mainly by ultraviolet radiation, the layers of polyethylene that cover aluminum are totally destroyed and the latter recovers its reflective characteristics, reaching emissivity values of 0.05 (this value was confirmed by the authors of the present paper through emissivity measurement tests performed within the scope of this study). The thermal blankets can be made by sealing or by sewing cartons, usually of milk, which were previously opened, flattened and cleaned (Fig. 2). The most common practical application of these blankets is as roof lining in which the aluminum face is facing downwards.

These packages can also be used for the production of roof tiles known as eco-tiles (Fig. 3).

Another example of recycling of products containing aluminum foils refers to toothpaste tubes which can also be used for the production of eco-tiles. In the project developed by the Institute for the Development of Ecological Housing in Brazil [9] tubes of tooth-

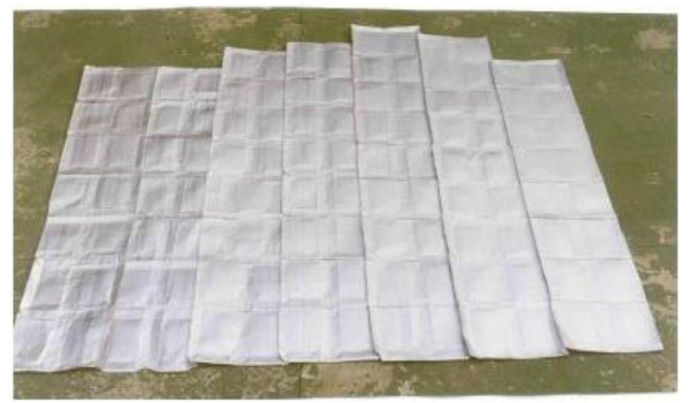

Fig. 2. Thermal blankets made out of old liquid food cartons [7].

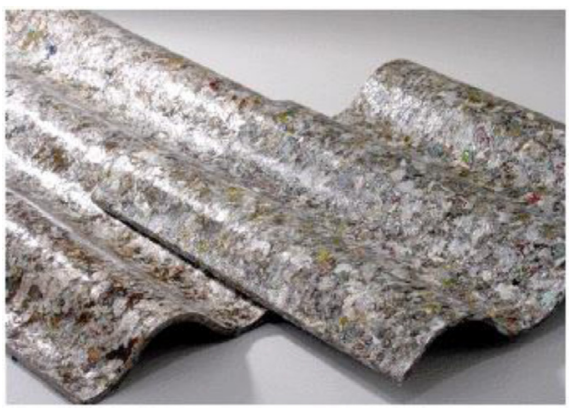

Fig. 3. Roof tile produced with old liquid food cartons [8].

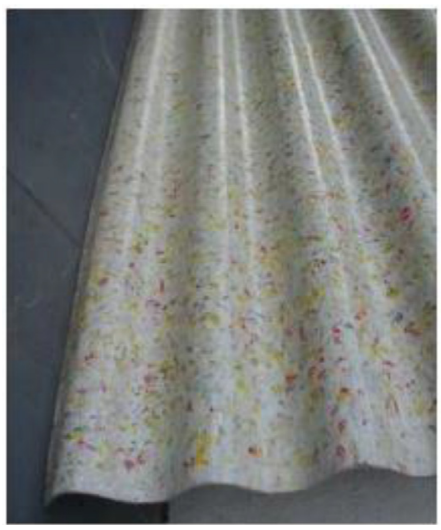

Fig. 4. Eco-tile produced with toothpaste tubes [9].

paste were used (those that did not pass in the quality control of the producing companies for their current use and were rejected). The used tubes have a composition of about $75 \%$ of polyethylene and $25 \%$ of aluminum (Fig. 4).

An even more direct use is the application of empty packages on the attic floor slab, creating a radiative and resistive insulation effect, due to the air space inside of the packages (Fig. 5).

\section{Objectives of the research}

From what was said in Section 1, the use of radiant barriers in buildings is one of the possible attempts to provide new and existing buildings with better thermal performance characteristics in order to simultaneously meet the comfort requirements of its users, a rational use of energy, a reduction of greenhouse gas emissions and the avoidance of construction pathologies.

To meet the comfort requirements of users and thermal legislation requirements, radiant barriers usually need to be used in complement with a "conventional" thermal insulation.

It is known that a significant part of the heat exchanges between indoor and outdoor environments occurs through the roofs 


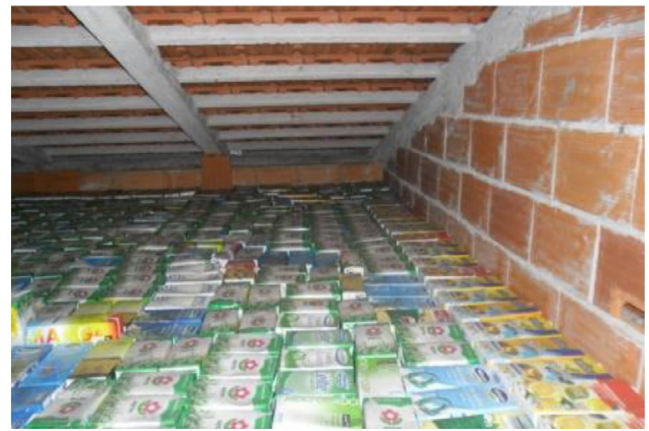

Fig. 5. Application of empty liquid food cartons on the floor of the roof attic.

of the buildings and that, especially in summer, the heat transfer by radiation can be quite significant given the high temperatures reached by the construction elements during that season. Therefore, a study on the application in building roofs of insulation materials with an effect on heat transfer by radiation was carried out.

Although these techniques have already been commonly used in other areas of science and technology, from the development of the simple thermos bottle to the most sophisticated device in the aerospace industry, the truth is that, except for some countries where the application of radiant barriers has been the subject of research, standardization and operationalization, in general, these kind of products still raise a number of doubts as to its potential for application in buildings.

Difficulties in assessing the real advantages of the application of radiant barriers in buildings have been found by researchers. Due to those difficulties, these materials do not easily get CE marking. Besides, most of the thermal legislation is designed having resistive thermal insulation materials in mind and so the consideration of the effect of radiant barriers is difficult to take into account in the scope of regulatory compliance.

Added to this situation is some misleading marketing on the supposed performance of radiant barriers as an alternative thermal insulation material, this did not contribute to clarifying their real effect among the technical and scientific communities related to the construction sector.

In this context, this paper presents part of a wider study which had the following main goals:

- To apply concepts of physics of radiation and heat transfer to the study of radiant barriers performance;

- To define a more comprehensive concept of thermal insulation material, including the characteristics and operation of resistive insulation and also of radiant barriers;

- To identify the various types of radiant barriers, differentiating their constitution, their characteristics and the methodology of application on site, including the reuse of products with other previous purposes;

- To carry out in-situ experimental measurements testing the application of radiant barriers in roofs in a temperate climate;

- To perform numerical simulations with CAPSOL software for a parametric study of the application of radiant barriers in roofs, in various climatic conditions;

- To establish guidelines for best practices adapted to each climatic region (based on similar studies [10]).

\section{Theoretical approach}

As it is well known, much of the radiation, such as infrared thermal radiation, is emitted due to changes in the electronic configurations of the atoms or molecules that make up matter. It is accepted that the energy associated with this radiation is trans- mitted through electromagnetic waves or photons [11]. Within the radiation spectrum, the most energetic is cosmic radiation.

The part of the spectrum associated with heat transfer, known as thermal radiation, ranges approximately between 0.1 and $100 \mu \mathrm{m}$ wavelength, integrating part of the ultraviolet radiation and the whole visible and infrared radiation. The emission spectra of a body depend on its temperature, hence they are often referred to as thermal spectra, and the higher the temperature of the body the more energetic the radiation emitted by it.

Infrared radiation, which is non-ionizing such as visible radiation, was first detected in 1800 by Sir William Herschel (17381822) [12].

Any body whose absolute temperature is above zero Kelvin emits infrared radiation, which means radiation at low frequencies (long wavelengths) and in the form of heat [13]. The infrared region extends approximately from $0.7 \mu \mathrm{m}$ to $100 \mu \mathrm{m}$ [11] and is usually subdivided into three regions according to their proximity to visible radiation: near-infrared, mid-infrared and far-infrared radiation. In terms of thermal sensation, near infrared radiation is not noticeable by human sensitivity. On the contrary, intermediate infrared and especially far infrared radiation are mainly responsible for human thermal sensations.

The transmission of heat through the envelope of the buildings occurs, as it is known, through three different mechanisms: the conduction, the convection and the radiation. The numerical simulation programs used by building physics researchers try to reproduce, in a more or less detailed way and a more or less accurate approach, what happens in the physical models.

CAPSOL [14], the software used in the scope of this study, is a computer program that simulates heat transfer in multi-zone situations in both steady state and dynamic regime. The heat transfer is simulated in one dimension (1D) and the heat transfer by infrared radiation can be modeled based on the use of view factors. The CAPSOL software allows also the consideration of multi-zone ventilation as well as the influence of direct and diffuse solar radiation.

CAPSOL is based on a network of thermal resistances and thermal capacitors, where boundary conditions are applied to calculate the temperatures in the nodes and heat flows in and between the nodes. The boundary conditions applied are: the known zone temperatures applied in the respective zone nodes; the solar heating powers injected in the wall and zone nodes; the heat dissipated by people, lighting and devices in the internal zones; the infrared sky radiation powers and the inter-zonal mass flows. Each building element (designated by wall) is represented by a series of resistances and capacitors and their possible cavities can be simulated using a convective resistance parallel to a radiative resistance or using one equivalent thermal resistance.

Regarding the resolution of problems associated with heat transfer by conduction, it is necessary to consider a general equation that relates the heat fluxes that cross each point of the construction elements to the rate of change of their internal energy [15]. CAPSOL works with 1D-conduction in transient regime.

With respect to heat transfer by convection, it is common, in a simplified way for small temperature differences, to calculate it using Newton's cooling law [16]. This law, which seems simple, nevertheless contains all its complexity in determining the coefficient of convection, $h^{\prime}$. As an approximation, $2.5 \mathrm{~W} /\left(\mathrm{m}^{2} . \mathrm{K}\right)$, is the value that is commonly used for the convective coefficient for indoor surfaces $\left(h_{\mathrm{ci}}\right)$ in thermal simulation programs, as is the case of CAPSOL [14], and corresponds to the $h_{\mathrm{ci}}$ value given in ISO 13789 [17] and ISO 6946 [3] for horizontal heat flow.

When an amount $\mathrm{G}\left(\mathrm{W} / \mathrm{m}^{2}\right)$ of irradiated energy reaches the surface of a body it is partially absorbed ( $\alpha . G)$, another part is reflected $(\rho . G)$ and the remaining part can be transmitted through the body. This distribution of the incident energy can be expressed 


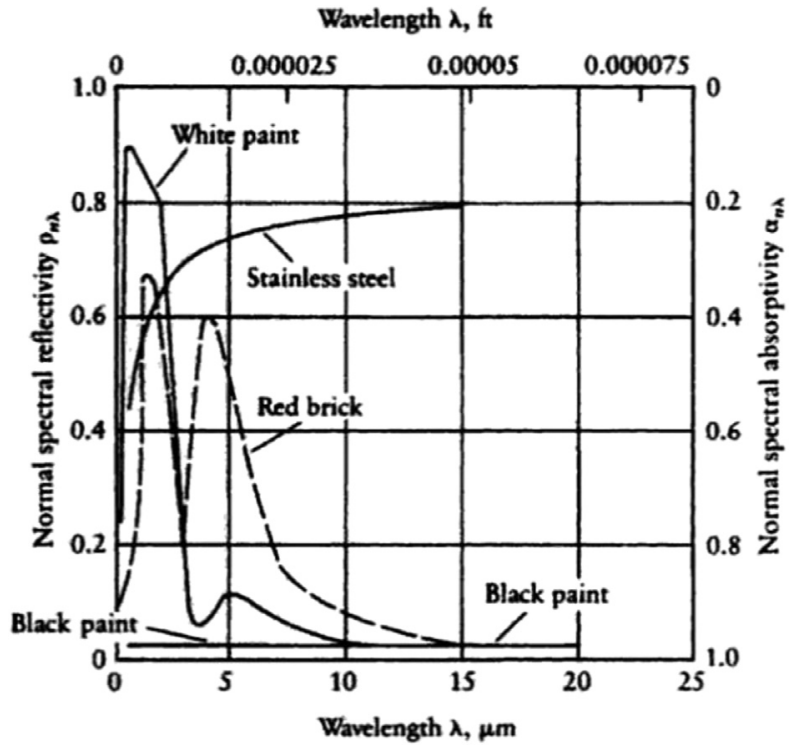

Fig. 6. Variation of normal spectral reflectivity and normal spectral absorptivity with wavelength for various opaque surfaces [18].

as follows:

$\mathrm{G}=\alpha \cdot \mathrm{G}+\rho \cdot \mathrm{G}+\zeta \cdot \mathrm{G}$

Where:

- $\alpha$ is the coefficient of absorption or total absorptivity;

- $\rho$ is the coefficient of reflection or total reflectivity;

- $\zeta$ is the coefficient of transmission or total transmissivity.

If the body is opaque to the incident radiation, the phenomena go on only superficially, and the bodyś transmissivity is null, i.e. $\zeta=0$, resulting in:

$\alpha+\rho=1$

If the surface of a solid body is at the absolute temperature $T_{w}$ and if it is completely surrounded by another solid surface which is at the absolute temperature $T_{\text {sur }}$, lower than the first, and if these surfaces are separated by a fluid which may be considered nonabsorbent, the heat flux by radiation $\mathrm{q} / \mathrm{A}$ (in $\mathrm{W} / \mathrm{m}^{2}$ ) of the surface at the temperature $\mathrm{Tw}$ to the surface at $\mathrm{T}_{\text {sur }}$ temperature is given by the following expression known as the Stefan-Boltzmann Law:

$\frac{q}{A}=\varepsilon \sigma\left(T_{w}^{4}-T_{\text {sur }}^{4}\right)$

where:

- $\varepsilon$ is the total emissivity of the solid surface at absolute temperature $T_{w}$;

- $\sigma$ is the constant of Stefan-Boltzmann whose value is equal to $567051^{*} 10^{-8} \mathrm{~W} /\left(\mathrm{m}^{2} \mathrm{~K}^{4}\right)$;

- A is the area (in $\mathrm{m}^{2}$ ) of the solid surface at $T_{w}$.

In Fig. 6, the variation of normal spectral reflectivity and normal spectral absorptivity with wavelength, for various opaque surfaces, is shown.

The heat transfer by radiation between surfaces depends mainly on their geometry and orientation, their radiant properties and their temperature. Generally, the quantification of this transfer presupposes that between these surfaces there is a non-participant means. The great majority of gases fulfill this condition. For the calculation of the exchange of radiation between surfaces, the concept of Form Factor or View Factor is used which basically is the percentage of radiation that leaves a surface $i$ and reaches a surface $\mathrm{j}\left(d q_{i \rightarrow j}\right)$. CAPSOL calculates heat exchanges by radiation using
View Factors. To calculate the total radiation which leaves surface $\mathrm{i}$ and is intercepted by surface $\mathrm{j}\left(q_{i \rightarrow j}\right)$ the following expression is used:

$q_{i \rightarrow j}=J_{i} \int_{A_{i}} \int_{A_{j}} \frac{\cos \theta_{i} \cos \theta_{j}}{\pi R^{2}} d A_{i} d A_{j}$

where:

- $J_{i}$ is the radiosity of $d A_{\mathrm{i}}$;

- $\cos \theta_{i}$ is the cosine of the polar angle $\theta_{i}$ between the line segment joining the two elementary surfaces $d A_{i}$ and $d A_{j}$ and the normal $n_{i}$ to the surface $d A_{i}$ (Fig. 7);

- $\cos \theta_{j}$ is the cosine of the polar angle $\theta j$ between the line segment joining the two elementary surfaces and the normal $n_{j}$ to the surface $d A_{j}$ (Fig. 7);

- $\mathrm{R}$ is the distance between the two elementary surfaces $d A_{i}$ and $d A_{j}$ (Fig. 7).

The view factor $\left(F_{i j}\right)$ is the fraction of the radiation leaving the surface $i$ which is intercepted by the surface $j$ and it can be expressed as follows:

$F_{i j}=\frac{1}{A_{i}} \int_{A_{i}} \int_{A_{j}} \frac{\cos \theta_{i} \cos \theta_{j}}{\pi R^{2}} d A_{i} d A_{j}$

For the case of a cavity consisting of two surfaces 1 and 2, with temperatures $T_{1}$ and $T_{2}$, exchanging radiation only between each other, the net heat rate transferred from surface 1 to surface 2 is given by:

$\dot{Q}=\mathrm{q}_{12}=\frac{\sigma \mathrm{T}_{1}^{4}-\sigma \mathrm{T}_{2}^{4}}{\frac{1-\varepsilon_{1}}{\varepsilon_{1} \mathrm{~A}_{1}}+\frac{1}{\mathrm{~A}_{1} \mathrm{~F}_{12}}+\frac{1-\varepsilon_{2}}{\varepsilon_{2} \mathrm{~A}_{2}}}$

where:

- $F_{12}$ is the View Factor between the surfaces 1 and 2;

- $A_{1}$ and $A_{2}$ are the areas of surfaces 1 and 2;

- $\varepsilon_{1}$ and $\varepsilon_{2}$ are the emissivity values of surfaces 1 and 2 .

If there are several surfaces to constitute a cavity, as it is the case of the attics of roofs in the present study, the problem becomes more complex and it is often recommended to use the matrix calculation as it is the case performed by CAPSOL software. Ahead in paragraph 7, the results of the simulations performed with CAPSOL will be presented and discussed and further details of its model will be presented.

An important parameter related to heat transfer by radiation is the Mean Radiant Temperature which is the uniform surface temperature of the envelope of a virtual compartment in which the heat exchanges by radiation are the same as those observed in the real space. The Mean Radiant Temperature allows therefore the calculation of the heat exchanges between the human body in a room and the surfaces that surround it.

\section{Presentation of the case study and performed measurements}

The case study to be presented in this paper is a single-family detached house located in the municipality of Maia, district of Porto, Portugal. The experimental measurements were carried out in the summer of two different years. The outdoor air temperatures ranged from $13{ }^{\circ} \mathrm{C}$ to $37^{\circ} \mathrm{C}$ during the measurement periods, having an average value of about $22{ }^{\circ} \mathrm{C}$. The relative humidity varied from $24 \%$ to $99 \%$, with an average value of about $65 \%$ and solar irradiance varied between 0 and $1120 \mathrm{~W} / \mathrm{m}^{2}$.

The part of the dwelling under analysis in the first year summer was an East oriented en suite bedroom and the roof covering it (Figs. 8-10). Fig. 8 shows the plan of the sector of the building where the mentioned bedroom is located, quoted in meters. The 


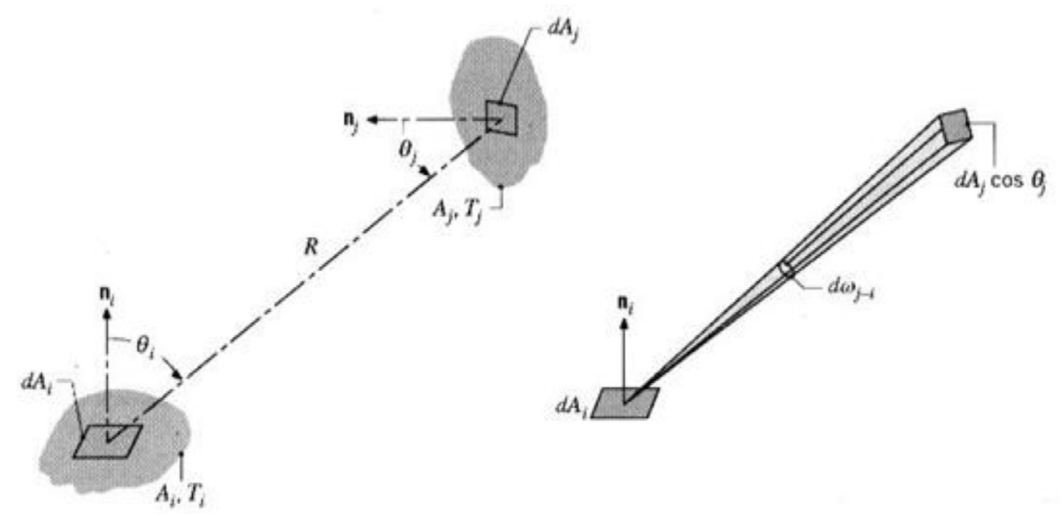

Fig. 7. Determination of the view factor associated with the heat exchange by radiation between surfaces [11].

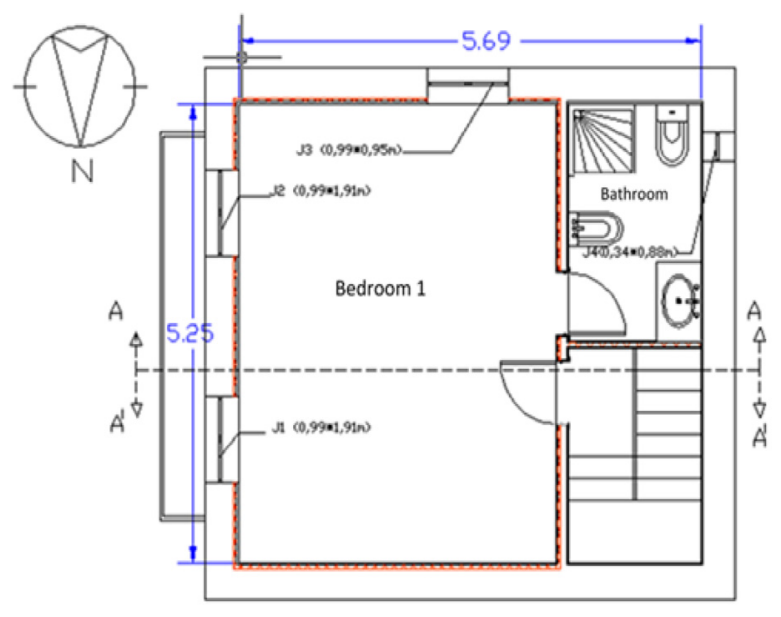

Fig. 8. Plan of the sector of the building under analysis in the 1 st year summer.

users of the room complain about thermal discomfort due to overheating on days with high outdoor air temperatures and intense solar irradiance.

Fig. 9 shows the cross-section A'-A' with the indication of the constitution of the various construction elements.

In Fig. 10, the eastern façade of the sector of the building under analysis is presented.

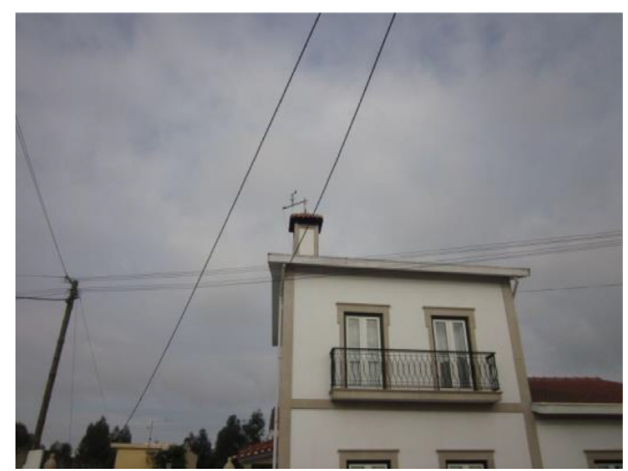

Fig. 10. Eastern façade of the sector of the building monitored in the 1 st year summer.

In the summer of the second year, in order to compare two similar roofs with different insulation solutions, another part of the house was also monitored which was a West oriented bedroom and the roof covering it (Figs. 11 and 12). The plan of that part, quoted in meters, is shown in Fig. 11.

The two described sectors of the house (eastern and western bedrooms under pitched roofs) were chosen because they are very similar and allow for comparisons. However, they aren't equal. The pitched roof of the western part is slightly bigger. In terms of volume, the attic of the western roof is $6 \%$ bigger than the eastern one.

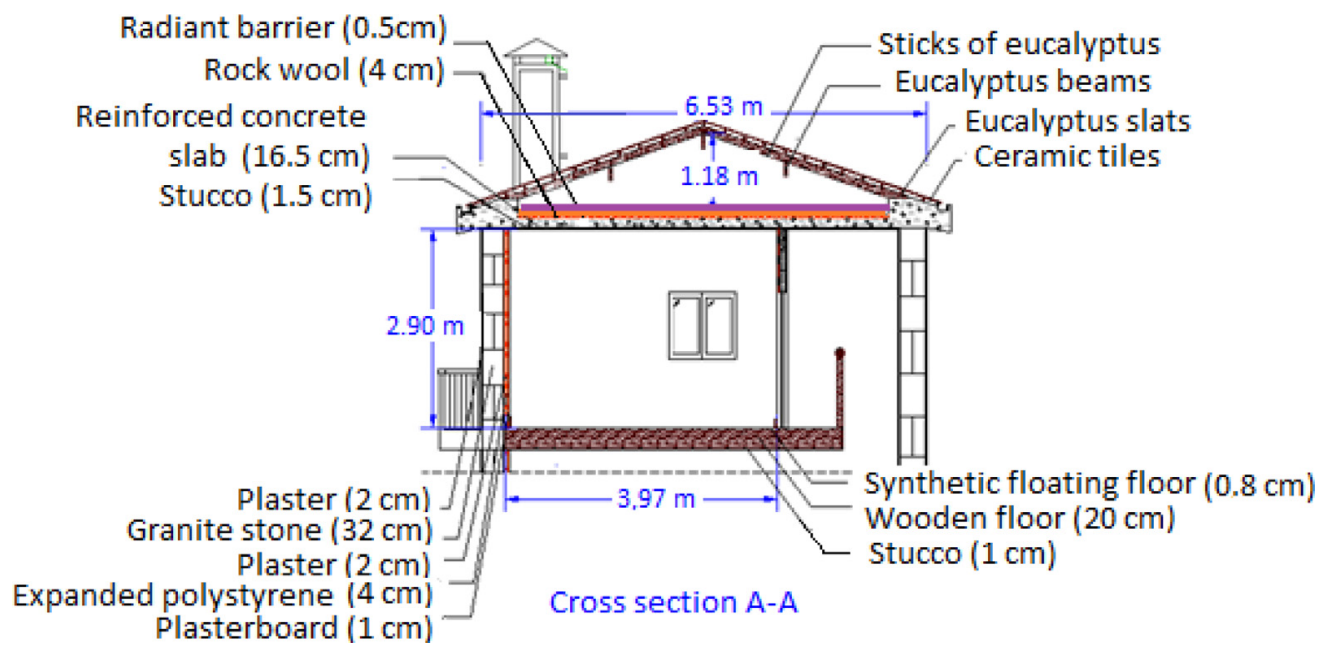

Fig. 9. Cross section A-A of the sector of the building under analysis in the 1st year summer. 


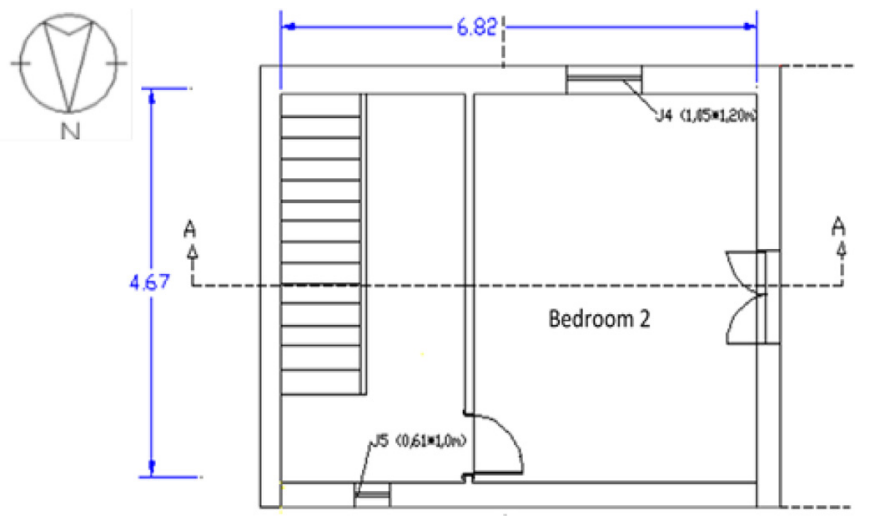

Fig. 11. Plan of the sector of the building monitored in the 2nd year summer.

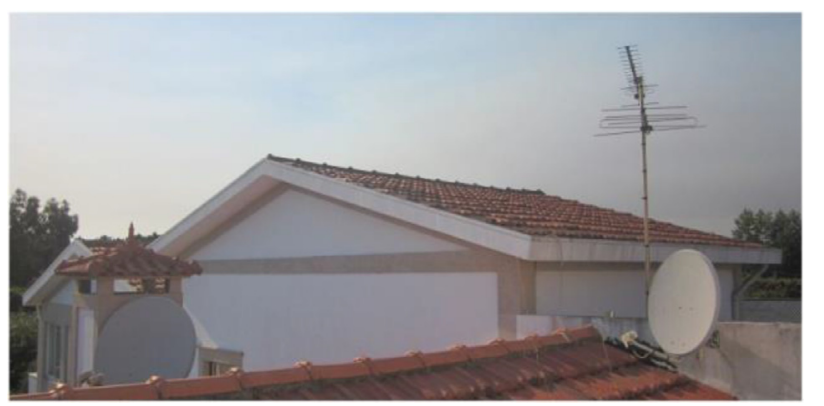

Fig. 12. Western part of the detached house under analysis in the 2nd year summer.

The slits of a considerable size existing between the roof tiles provide conditions so that both roof attics are strongly ventilated. As it can be seen in Figs. 9 and 12, the two monitored bedrooms show some differences in glazing, namely in terms of number and orientation of the windows.

The façades of both sectors are in masonry made of yellow granite from Mondim, externally rendered with traditional plaster, except for the areas of wedges, shoulders, lintels, sills and slabs. The internal surface of the exterior walls was covered by about $2 \mathrm{~cm}$ thick of traditional plaster in cement which was later overlaid by a panel composed of $4 \mathrm{~cm}$ of expanded polystyrene glued to $1 \mathrm{~cm}$ thick of plasterboard. The window frames are in PVC with double glazing. All windows, except for the bathroom, have interior aluminum opaque coverings.

The floor slab of the bedrooms is composed of a wood structure coated by an original old pine floor. It was recently renovated with the application of a synthetic floating floor over the existing one. An expanded polyethylene film was placed between the pine floor and the synthetic floor. On the underlying floor ceiling there is a lining consisting of wooden slats impregnated with gypsum plaster and sisal. The bedrooms ceiling slab consists of prestressed concrete beams and ceramic hollow blocks, top coated with a heavy concrete layer, thermally insulated at the upper level with a $4 \mathrm{~cm}$ thick rock wool blanket on the eastern part of the detached house and a $4 \mathrm{~cm}$ thick panel of extruded expanded polystyrene on the western one. The thermal behavior of the rock wool blanket (MW) and the panel of extruded expanded polystyrene (XPS) is very similar, both having a thermal conductivity coefficient of $0.04 \mathrm{~W} /\left(\mathrm{m}^{\circ} \mathrm{C}\right)$. Later a $0.5 \mathrm{~cm}$ thick radiant barrier, consisting of a sandwich of two foils of thermolaminated aluminum, with low density non crosslinked polyethylene foam (also with a thermal conductivity coefficient of $0.04 \mathrm{~W} /\left(\mathrm{m}^{\circ} \mathrm{C}\right)$ ) between them was applied over the rock wool. The used aluminum foils have a declared total emissivity of

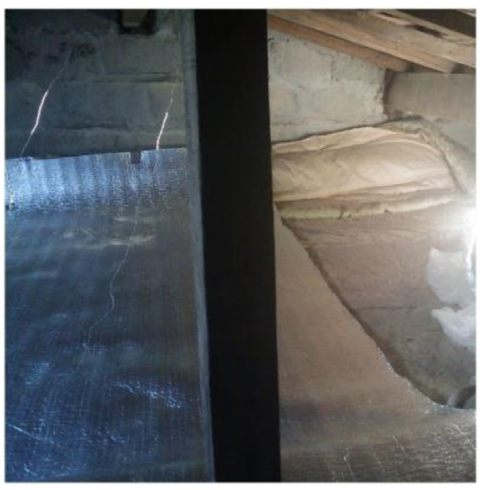

Fig. 13. Inside the attic of the eastern roof during the application of the radiant barrier.

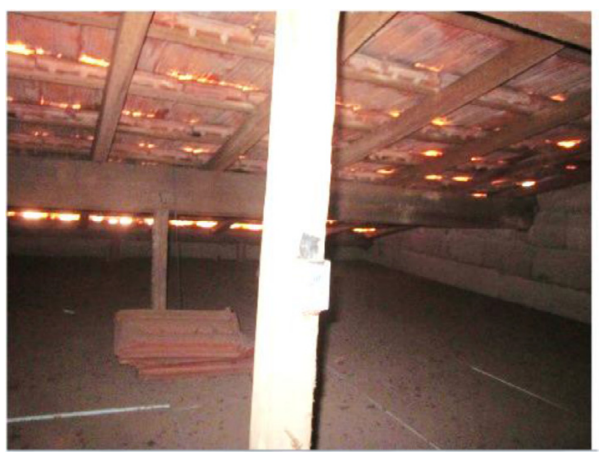

Fig. 14. Inside the attic of the western roof.

0.06 [6]. The authors confirmed this value through emissivity measurement tests performed within the scope of this study.

The roof of the eastern part of the house monitored in the first year presents two slopes with a wooden support structure of eucalyptus. The roof covering is of ceramic tiles of Marseilles type. The external walls of the roof attic are made of solid concrete blocks with a total thickness of $31 \mathrm{~cm}$, covered externally by $2 \mathrm{~cm}$ of cement mortar. In Fig. 13, the interior of the eastern roof attic can be seen during the application of the radiant barrier.

Regarding the western roof monitored in the second year, it integrates $4 \mathrm{~cm}$ of XPS as thermal insulation above the floor slab instead of the rock wool used in the eastern roof. Furthermore, no radiant barrier was applied in the western roof. Fig. 14 shows an image of the interior of the western roof attic where the XPS thermal insulation panels cover the floor.

The objective of this study was, in the first year of experimental measurements, to compare the thermal performance of the eastern roof and the bedroom underneath, with and without the application of a radiant barrier. Thus, there was a first phase of measurements (in the second half of August) before the application of the radiant barrier and a second phase (in the first half of September) after the application of the radiant barrier over the existing blanket of rock wool.

In the second year summer, the two roofs were simultaneously monitored. The eastern roof kept the radiant barrier that had been applied in the first year, with no further modification in a first phase. In a second phase, radiant barriers were additionally applied under the roof slopes, as shown in Fig. 15. The western roof was maintained with its original configuration during the whole period of measurements, which means with no radiant barrier.

For the execution of the measurements in situ in the two years of study the following equipment were used: 


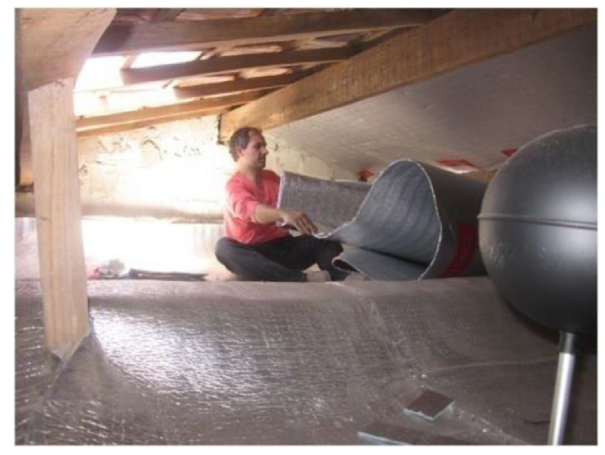

Fig. 15. Application of radiant barriers under the eastern roof slopes.

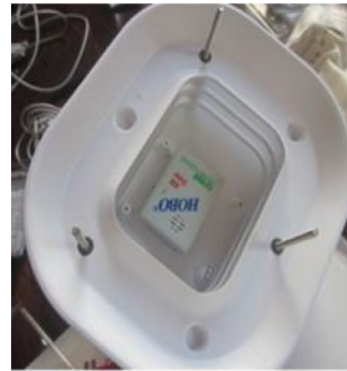

(a)

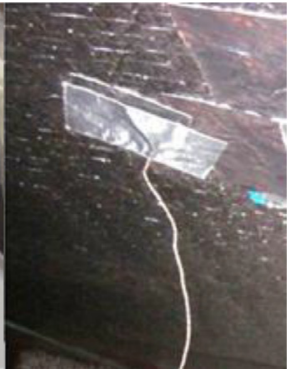

(b)
Fig. 16. (a) Protection shield against solar radiation for outdoors sensors (b) Type T thermocouple applied to the surface of the radiant barrier under the roof slope.

- Two dataloggers with 16 analog channels (includes analogue input-sockets with 14 pins - An ports), two channels of impulse of frequency (these IF ports have 12 pins) and one digital port (the Dig port has 12 pins). These three port-types are laid out on the datalogger so that is possible to attach and supply the maximum number of sensors directly and without the need of special adaptors;

- Air temperature sensors with built-in logger. In the summer of the first year, three temperature sensors were used that incorporate a logger of data storage: one outdoors, another one in the roof attic and a last one in the bedroom;

- Temperature and humidity sensors with built-in logger. In the summer of the second year, five sensors of this type were used: three in the eastern part of the house; one in the bedroom, one in the roof and the other one outdoors; and two in the western part of the house; one in the bedroom and another in the roof attic. As for the sensors used outdoors, they were placed in a protective shield against solar radiation (Fig. 16a);

- Type $\mathrm{T}$ thermocouples (where the positive wire is copper and the negative wire is a copper and nickel alloy), for the measurement of the surface temperature of some building elements. In the summer of the first year, five thermocouples were used: two of them were used to measure the temperature of the lower surface of the roof tiles; two other T-type thermocouples were used to measure the temperature of the upper surface of the floor slab of the roof attic and a last one was applied to the lower surface of the same slab in order to measure the surface temperature of the bedroom ceiling. In the summer of the second year, a total of seven thermocouples were used: four of them were used in the eastern part of the dwelling and three in the western zone. In the eastern part of the house, thermocouples were applied to the ceiling of the bedroom, on the upper surface of the ceiling slab (more specifically over the radiant barrier), on the lower surface of the roof tiles and on the lower surface of the additional radiant barrier which was placed un-

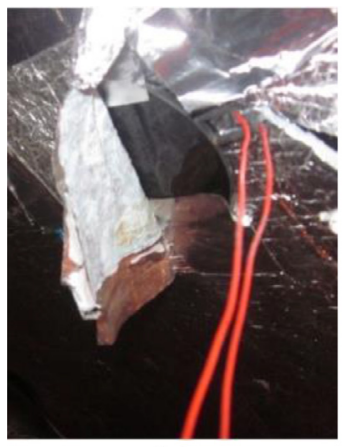

(a)

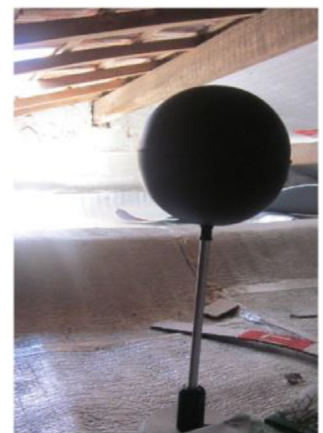

(b)
Fig. 17. (a) Heat flux sensor applied to the surface of the radiant barrier under the roof slope (b) Black bulb thermometer.

der the roof slopes (Fig. 16b). In the western part of the house, thermocouples were applied to the ceiling of the bedroom, on the upper surface of the ceiling slab (over the XPS) and on the lower surface of the roof tiles;

- Heat flux sensors made of polyurethane. In the summer of the first year, heat flux sensors were used to measure the heat flux through both the roof slopes and the bedroom ceiling slab. In the summer of the second year, five heat flux sensors were used, three in the eastern roof and two in the western roof. In the eastern roof, they were applied on the upper surface of the bedroom ceiling slab, on the lower surface of the roof tiles and on the lower surface of the additional radiant barrier which was placed under the roof slopes (Fig. 17a). In the western roof, a heat flux sensor was applied to the upper surface of the XPS and another one to the lower surface of the roof tiles. These locations of the heat flux sensors aimed to measure the heat fluxes at various levels (roof slopes, ceiling slab and radiant barrier, when it existed) in order to compare heat flux values between situations with and without radiant barrier and the effect of its application for the whole construction. Also in the second year summer and as a complementary study, a heat flux sensor was used, underneath a set of empty packages for liquid food cartons, in order to make a preliminary test of these packages as thermal insulation material;

- Black bulb thermometer which is a thin metal black globe with a Ni100 resistant element inside. This equipment was used in the summer of the second year to measure the mean radiant temperature of the eastern roof attic (Fig. 17b);

- Pyranometer, for measuring total horizontal solar irradiance, which can measure flows up to $2000 \mathrm{~W} / \mathrm{m}^{2}$;

- Anemometer and wind vane, for measuring wind speed and direction, whose wind speed measurement range is 0.5 to $50 \mathrm{~m} / \mathrm{s}$. This equipment was used in the first year summer.

Figs. 18-21 show a plan and cross-sections of the eastern part of the house that illustrate the location of the equipment used for the experimental measurements. Fig. 22 is a cross-section of the western sector.

\section{Results analysis: first campaign}

In order to be able to characterize and compare the performance of the Eastern roof and the bedroom that underlies it, in the absence and the presence of a radiant barrier installed over the attic floor slab (horizontal radiant barrier - HRB), since it was not possible to carry out these measurements simultaneously, several strategies were developed successively encompassing choices of representative measurement periods. These strategies correspond to three steps of comparisons which are briefly summarized below. 


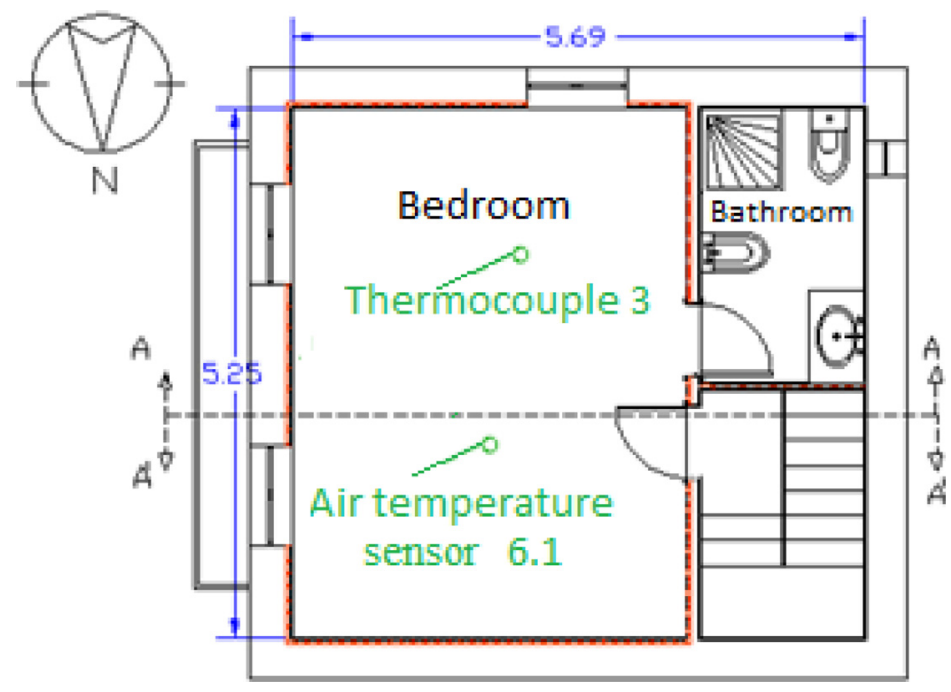

Fig. 18. Plan of the eastern sector with equipment location in the 1 st year summer.

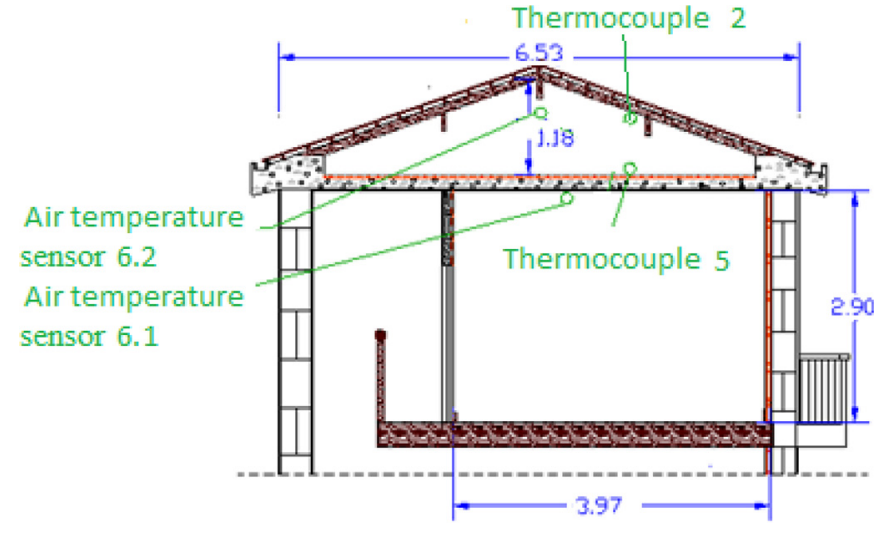

Fig. 19. Cross-section $A=A^{\prime}$ of the eastern sector with equipment location in the 1 st year summer.

In a first step, the whole measurement periods were considered, before and after the application of the radiant barrier (for the situation without the radiant barrier, the measurement period went from August 17 at 10:30 p.m. until August 31 at 7:20 p.m. and for the situation with the radiant barrier, that period went from September 2 at 5 p.m. until September 15 at 4 p.m.). This step

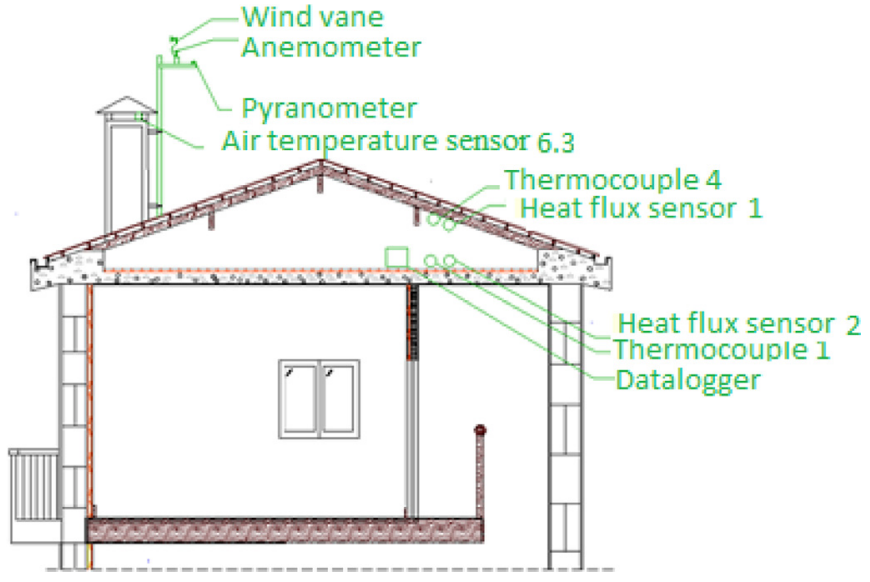

Fig. 20. Cross-section A - A of the eastern sector with equipment location in the 1 st year summer.

therefore consisted in using all the available data gathered from the performed measurements. In the situation after the application of the radiant barrier, for the same mean value of the outdoor air temperature and for a very similar total horizontal solar irradiance,

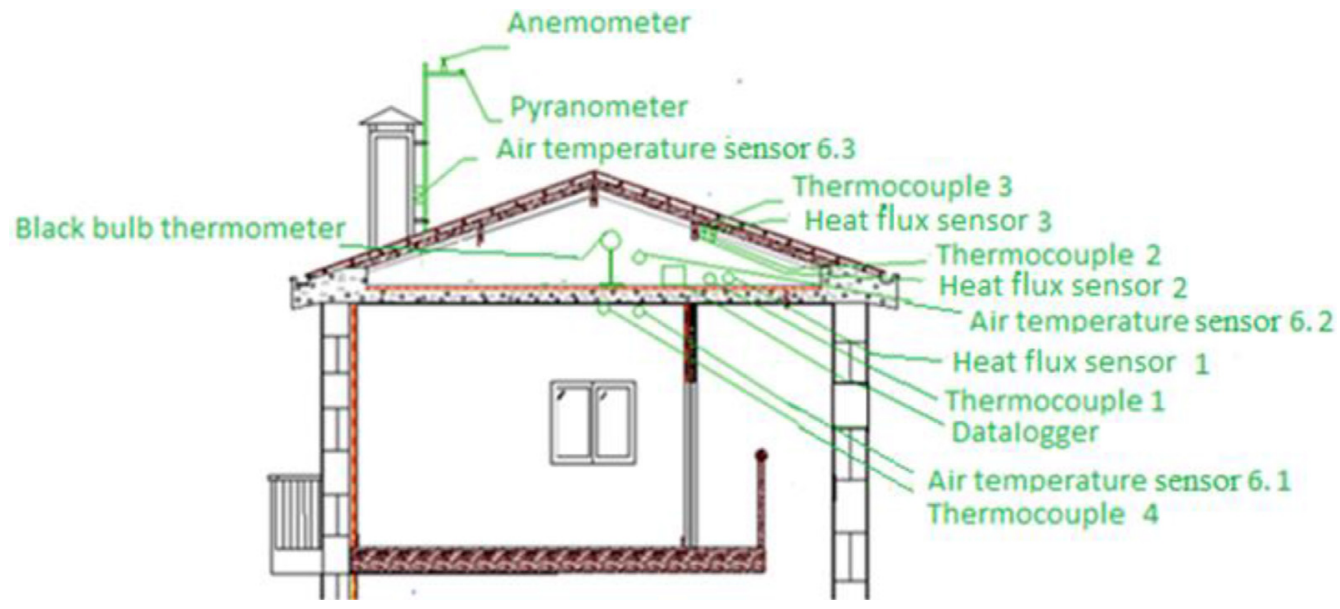

Fig. 21. Cross-section $A-A$ of the eastern sector with equipment location in the 2 nd year summer. 


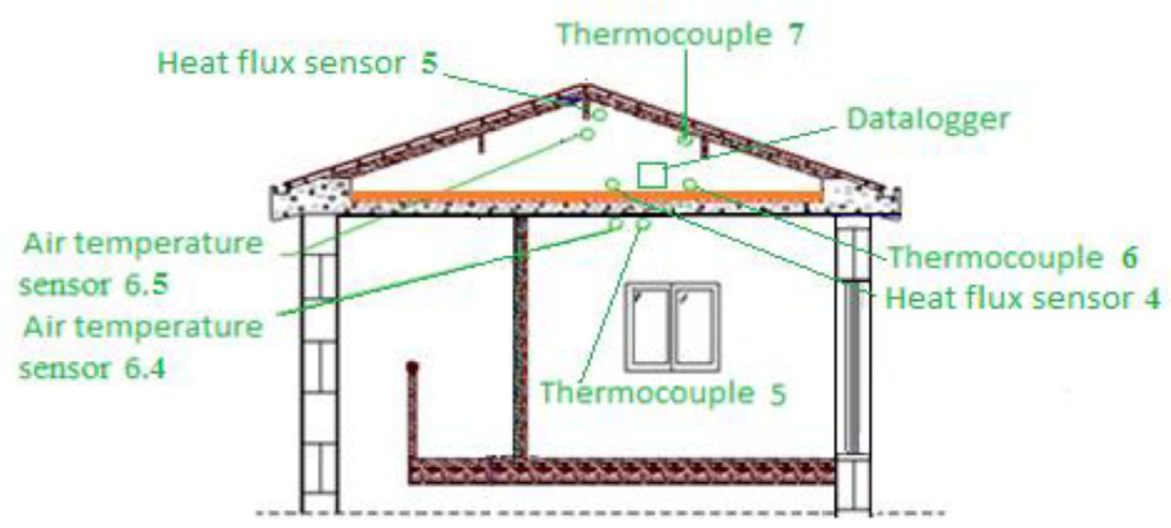

Fig. 22. Cross-section A - A of the Western sector with equipment location in the 2nd year summer.

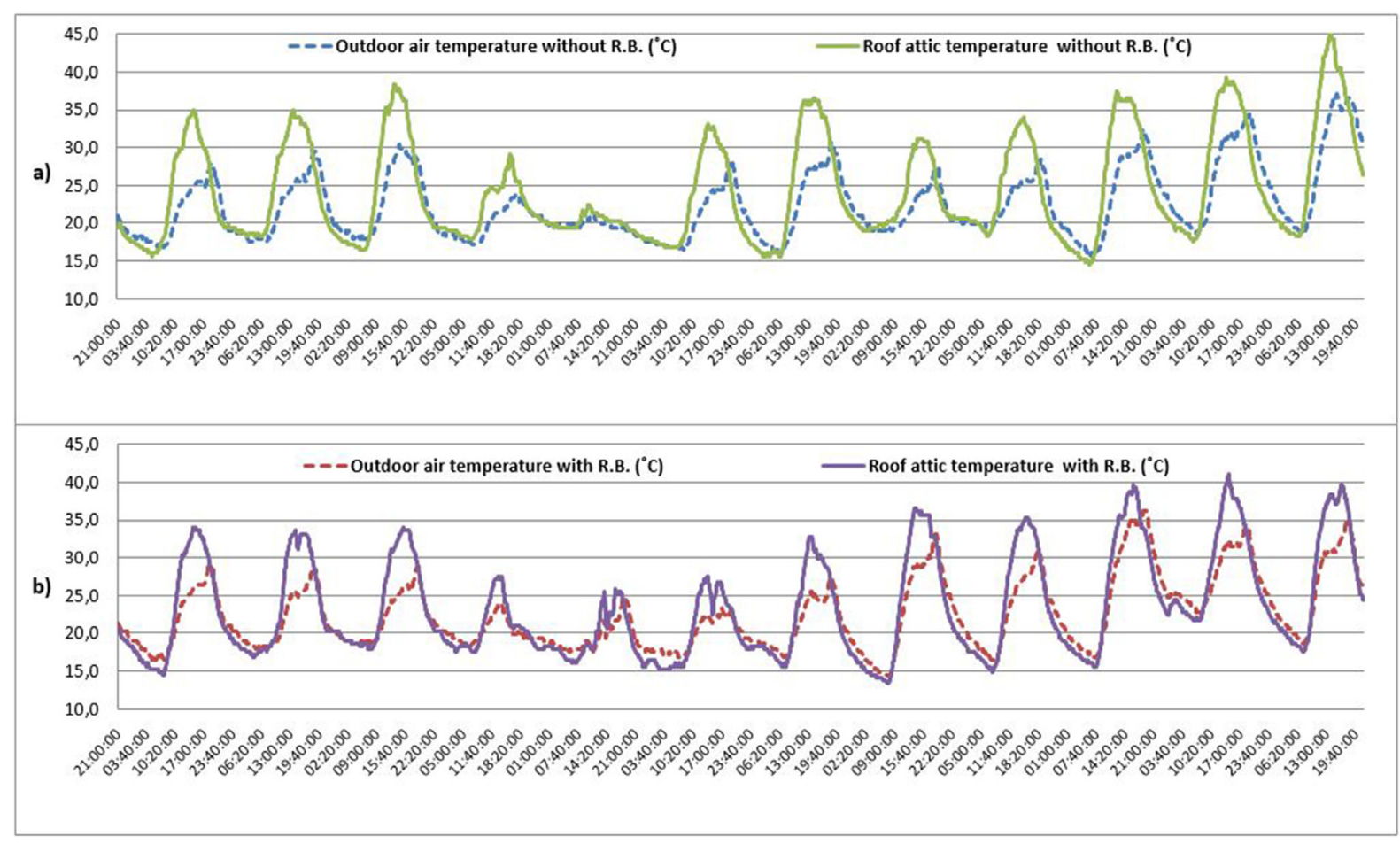

Fig. 23. Outdoor air temperature and roof attic temperature: a) Without radiant barrier; b) With radiant barrier.

in comparison to the period before that application, the mean temperature of the roof attic is lower by $1.1^{\circ} \mathrm{C}$, the mean temperature of the bedroom is lower by $0.4{ }^{\circ} \mathrm{C}$ and the mean surface temperature of the bedroom ceiling is lower by $0.5{ }^{\circ} \mathrm{C}$. With regard to the maximum values, in the situation with the radiant barrier, the maximum temperature of the roof attic is lower by $4.3^{\circ} \mathrm{C}$, the maximum temperature of the bedroom is lower by $3.6{ }^{\circ} \mathrm{C}$ and the maximum surface temperature of the bedroom ceiling is lower by $2.2{ }^{\circ} \mathrm{C}$.

In a second step, shorter periods were considered, contained in the previous ones and, where possible, with similar characteristics. However, since the measurements to be compared were performed at successive and non-simultaneous times, the climatic conditions, although similar, were different and there was also no control of the opening and closing of the windows, as this situation is dependent on the daily activity of the occupants of the bedroom. Obviously, this uncontrolled variation of ventilation flow rates and internal heat gains caused by the occupants influences the comfort conditions of this space. Fig. 23 shows the variation of the out- door air temperatures and the temperatures of the roof attic for the considered periods of time: a) without radiant barrier and b) with radiant barrier.

Fig. 24 shows the variation of the outdoor air temperature and of the total horizontal solar irradiance, in the considered periods.

Something very evident in Fig. 24 is that the peak of the solar irradiance occurs before the peak of the outdoor air temperature, which clearly indicates that the solar radiation has an important influence on the maximum temperatures reached in the roof attic since, as it can be seen in Fig. 23, the maximum temperatures at the roof attic are always reached before the maximum outdoor air temperatures.

Regarding the temperatures and to conclude the analysis of the highest values, the instants were chosen in which outdoor air temperatures above $35{ }^{\circ} \mathrm{C}$ were reached in situations with and without radiant barrier. Table 1 shows the maximum values obtained for the outdoor air temperature, temperature of the roof attic and temperature of the bedroom. 


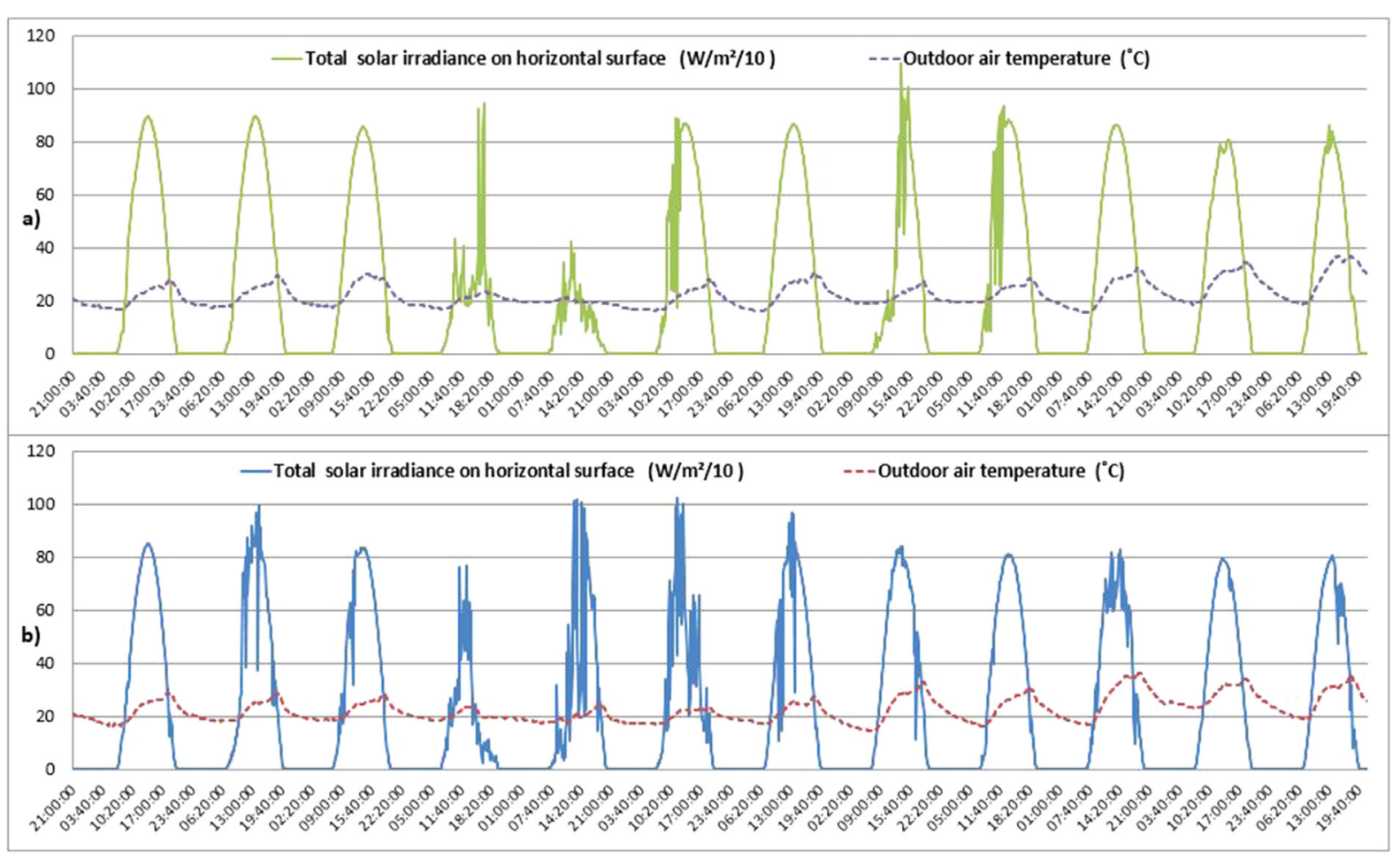

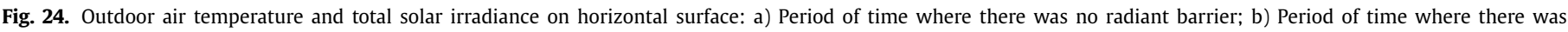
a radiant barrier.

Table 1

Maximum values of temperatures $\left({ }^{\circ} \mathrm{C}\right)$, in moments where outdoor air temperature was greater or equal to $35^{\circ} \mathrm{C}$, without and with a radiant barrier (RB).

\begin{tabular}{lllllll}
\hline & \multicolumn{2}{l}{ Outdoor air temperature } & \multicolumn{2}{l}{ Temperature of the roof attic } & \multicolumn{2}{c}{ Temperature of the bedroom } \\
& Without RB & With RB & Without RB & With RB & Without RB & With RB \\
\hline Maximum values & 37.0 & 36.1 & 44.9 & 39.7 & 29.9 & 26.3 \\
\hline
\end{tabular}

Regarding the maximum values reached, in the period where the radiant barrier was not applied, the maximum temperature in the bedroom was $3.6{ }^{\circ} \mathrm{C}$ higher than when there was a radiant barrier. However, it must be noted that the maximum outdoor temperature was only $0.9{ }^{\circ} \mathrm{C}$ higher in the period where the radiant barrier was not applied.

It is also important to analyze the dependence of the roof attic temperature and the bedroom temperature, in the face of solar irradiance. Thus, using only moments in which the total horizontal solar irradiance exceeded $900 \mathrm{~W} / \mathrm{m}^{2}$, it was verified that in average terms, during the period when the radiant barrier was in place, mean temperatures occurred in the attic of the roof and in the bedroom, lower in $2.7{ }^{\circ} \mathrm{C}$ and $0.9{ }^{\circ} \mathrm{C}$, respectively, when compared to the situation without the radiant barrier.

It should be noted that during the time periods analyzed above, there was no coincidence in terms of instants in which solar irradiance values were higher than $900 \mathrm{~W} / \mathrm{m}^{2}$ and outdoor air temperature was above $35^{\circ} \mathrm{C}$, so there were two different analyses.

In a third step of comparisons, account was taken of even shorter periods of time contained in the previous ones, where a near-coincidence of climatic conditions was sought and where it was ensured that the windows and doors were closed and the bedrooms unoccupied thereby to cancel the uncertainty caused by the variation of ventilation rates in the rooms and by the different internal gains over the period of use. A comparison of outdoor air temperatures, with and without the radiant barrier, was performed to select sub-periods with some temporal expression in which the
Table 2

Bedroom temperature in the selected periods of time.

\begin{tabular}{lll}
\hline & \multicolumn{2}{l}{ Bedroom temperature $\left({ }^{\circ} \mathrm{C}\right)$} \\
\cline { 2 - 3 } & Without RB & With RB \\
\hline Minimum values & 22.9 & 21.3 \\
Maximum values & 26.3 & 22.5 \\
Mean values & 23.7 & 22.0 \\
\hline
\end{tabular}

variation of the outdoor air temperature was as similar as possible (Fig. 25).

In Fig. 26, the variation of the temperature of the bedroom in the selected periods of time is presented.

In Fig. 26, it can be seen clearly that with the application of the radiant barrier, the temperature in the bedroom remains always below the temperature reached without that barrier. The characteristics of the temperature in the bedroom in the selected periods, with and without radiant barrier, are summarized in Table 2.

Since, for the existence of thermal comfort in the bedroom, the surface temperature of the ceiling is also of interest, the graph showing its variation over the time periods under analysis is shown in Fig. 27.

It was found that with the radiant barrier application the mean value of the surface temperature of the bedroom ceiling was about $1.8^{\circ} \mathrm{C}$ lower than the mean value found without such a barrier. 
M. Ferreira, H. Corvacho/Energy \& Buildings 176 (2018) 163-178

173

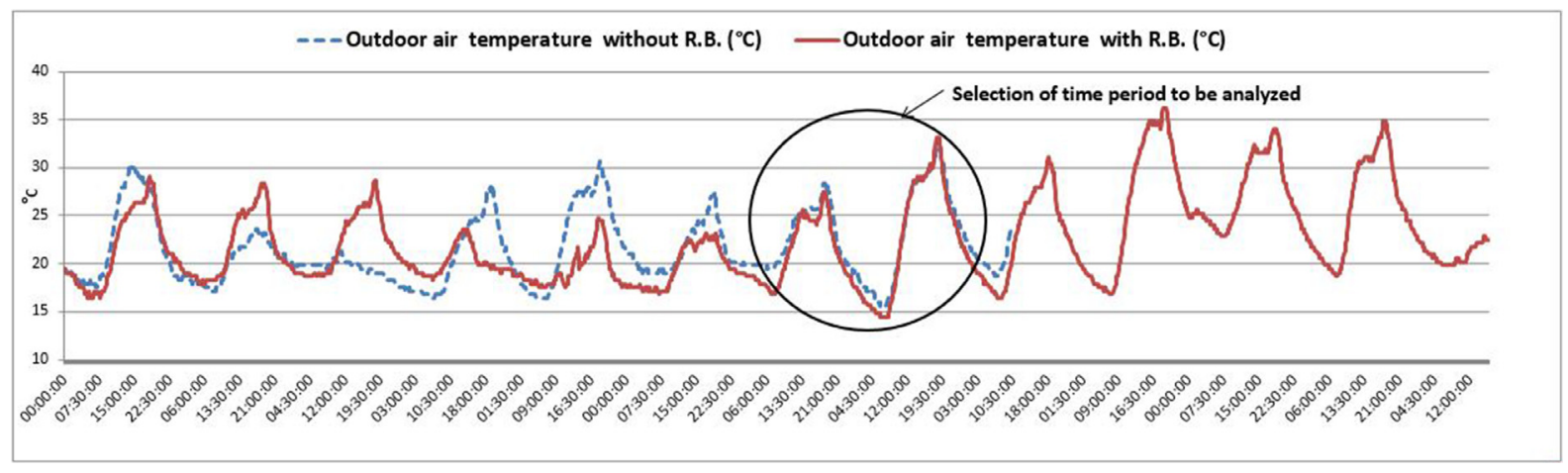

Fig. 25. Comparison between the measured values of outdoor air temperature and selection of time periods to be analyzed.

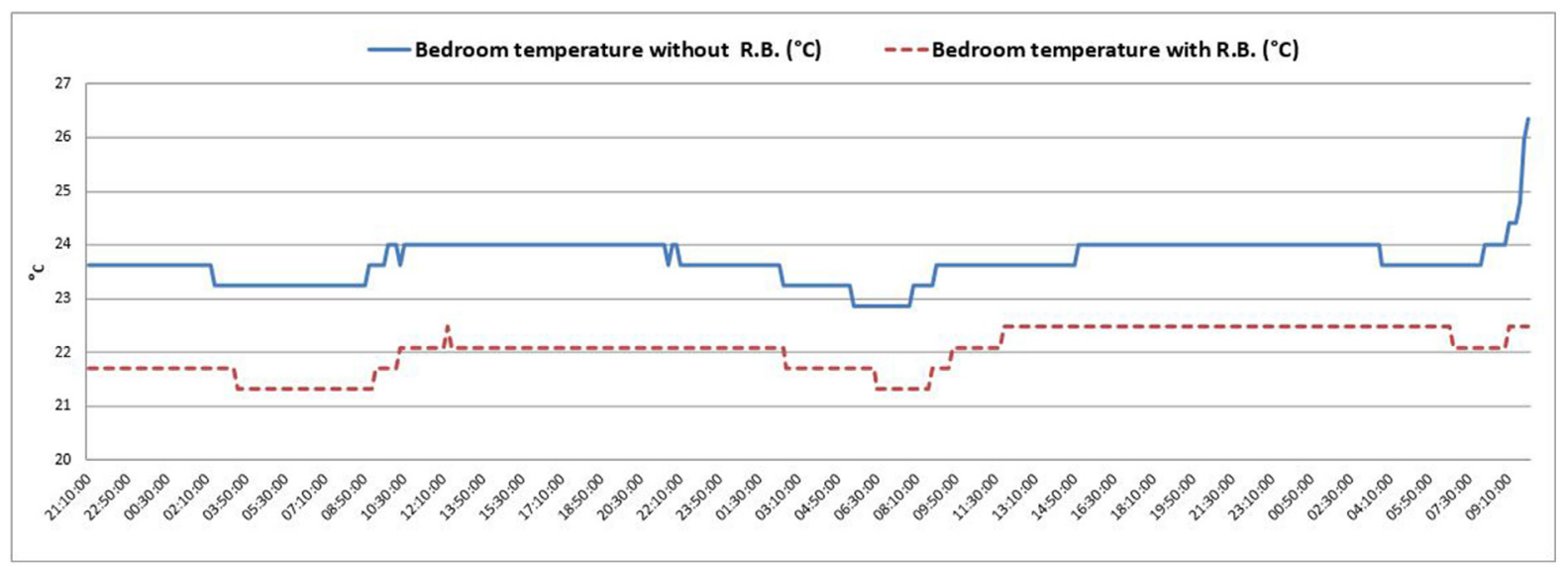

Fig. 26. Comparison between bedroom temperatures in the selected periods of time.

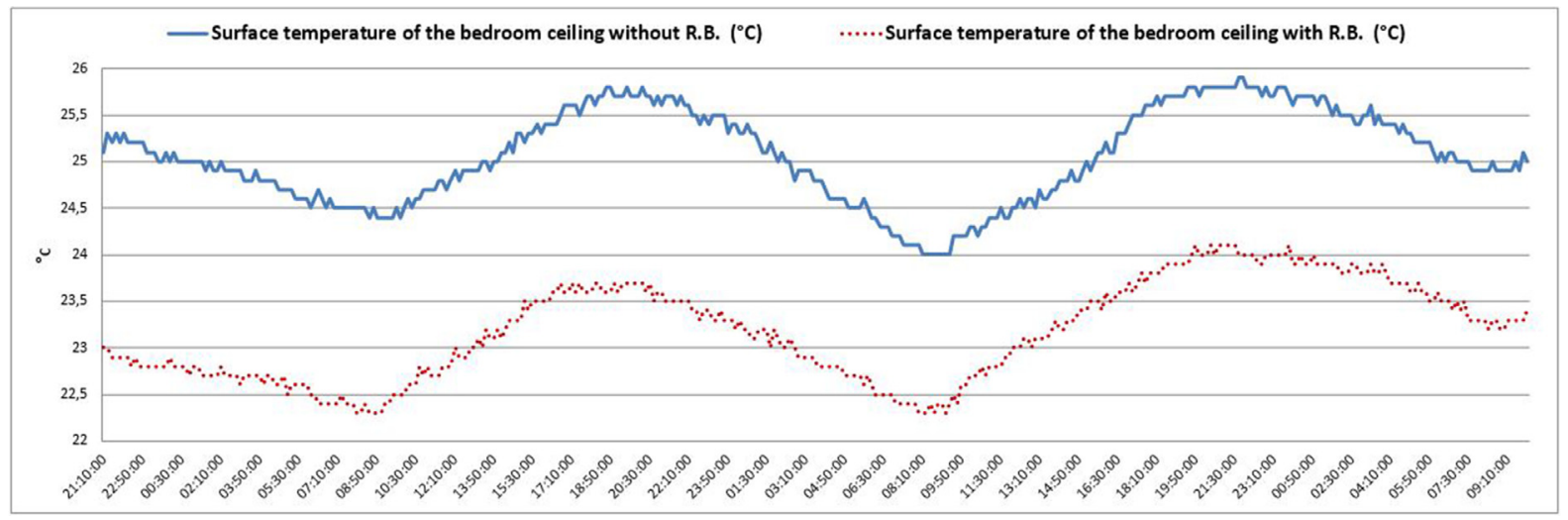

Fig. 27. Variation of surface temperature of bedroom ceiling in the selected periods.

6. Results analysis: second campaign

As mentioned earlier, in the summer of the second year, two housing sectors were monitored, with similar characteristics, with different insulation solutions, and data collection was carried out simultaneously. This procedure had the advantage of benefiting from the same climatic conditions but had the disadvantage of not being able to use the same space but just spaces with similar geometric, thermal and ventilation characteristics. In almost the whole measurement period, the rooms were kept unoccupied. On the few days when they had to be occupied, it was sought that the conditins were as similar as possible (equal number of occupants and avoiding the opening of the windows).

In the second year, the experimental measurements comprised three phases. In a first phase, besides the temperature sensors with builtin logger, a datalogger with 16 analog channels and two of impulse of frequency was used, in the absence and the presence of a radiant barrier installed over the attic floor slab (horizontal radiant barrier - HRB). The equipment (thermocouples, heat flux sensons, etc.) located in the two roofs attics and two bedrooms were connected to that datalogger.

In Table 3, the maximum and mean values of the measured surface temperatures of both roof slopes and floor slabs of the minitore roof attics are presented.

Comparing eastern roof with western roof, it can be observed that with the application of the radiant barrier to the upper surface of the floor slab, the maximum temperature in this surface was lower by $2.8{ }^{\circ} \mathrm{C}$ and at the roof slope, in the lower surface of the tiles, the maximum temperature was lower by $2.7^{\circ} \mathrm{C}$. As for the 
Table 3

Surface temperatures $\left({ }^{\circ} \mathrm{C}\right)$, in 2 nd year summer (first phase).

\begin{tabular}{|c|c|c|c|c|}
\hline & \multicolumn{2}{|l|}{ Western roof attic } & \multicolumn{2}{|l|}{ Eastern roof attic } \\
\hline & $\begin{array}{l}\text { Upper surface of the floor slab } \\
\text { without RB }\end{array}$ & $\begin{array}{l}\text { Lower surface of the roof slope } \\
\text { without RB }\end{array}$ & $\begin{array}{l}\text { Upper surface of the floor slab } \\
\text { with RB }\end{array}$ & $\begin{array}{l}\text { Lower surface of the roof slope } \\
\text { without RB }\end{array}$ \\
\hline Mean values & 23.7 & 24.8 & 22.9 & 24.1 \\
\hline
\end{tabular}

Table 4

Heat fluxes* $\left(\mathrm{W} / \mathrm{m}^{2}\right)$, in 2nd year summer (second phase).

\begin{tabular}{llllll}
\hline & \multicolumn{2}{l}{ Western roof attic } & & \multicolumn{2}{l}{ Eastern roof attic } \\
\cline { 2 - 3 } \cline { 5 - 6 } \cline { 5 - 6 } & Floor slab without RB & Roof slope without RB & & Floor slab with RB & Roof slope without RB \\
\hline Minimum values & -10.0 & -19.0 & -7.0 & -21.0 \\
Maximum values & 15.0 & 49.0 & 11.0 & 50.0 \\
\hline
\end{tabular}

* A negative value indicates an upward heat flux and a positive value indicates a downward heat flux.

mean temperature, it was lower by $0.8{ }^{\circ} \mathrm{C}$ in the floor slab and lower by $0.7^{\circ} \mathrm{C}$ in the lower surface of the roof slope.

In a second phase, in order to allow more measurement equipment to be used in the western roof attic, two dataloggers were used, one in each of the roof attics, one in the absence and other in the presence of a radiant barrier installed over the attic floor slab (horizontal radiant barrier - HRB).

In what regards the comparison of the heat fluxes that pass through both slopes and floor slabs of the two roof attics for the same period, the respective maximum and minimum values are given in Table 4.

It can be seen that the maximum heat fluxes that crossed the slabs, which are downward, reached the highest value on the western roof without radiant barrier, and the use of this barrier in the eastern roof allowed a decrease to $73 \%$ of that value. As for the minimum values, which are upward, it can be observed that the greatest absolute heat fluxes are also observed at the western roof, without a radiant barrier, and its use in the eastern roof allowed a decrease to $70 \%$ of that value. These results point out a lower potential need for cooling power in the presence of a radiant barrier. However, it should be borne in mind that, like any other insulation, the radiant barrier does not facilitate night-time cooling in summer and therefore cooling must be foreseen and promoted by other means such as night ventilation.

In a third phase, maintaining the two dataloggers of the previous phase in use, an additional (HRB remains) radiant barrier was applied to the lower surface of the slopes of the eastern roof (truss radiant barrier - TRB). The TRB solution allows to greatly reduce the amount of dust that is deposited in the radiant barrier placed in the attic floor slab, since most of the dust comes in through the tiles and the slits between them. On the other hand, this solution, having two highly polished aluminum films on the surfaces, one on the upper surface, which acts by reflection and the other on the lower surface that acts by low emissivity (and that will never be affected by relevant dust deposits) turns out to be more efficient than the HRB solution, which only has an aluminum surface in contact with air, in this case acting by reflection, and that loses its efficiency due to the accumulation of dust. Also, the position of the TRB prevents that a great amount of heat reaches the attic space. This, of course, represents a greater protection to the underlying rooms. All the measurements carried out in the second year were performed after cleaning the radiant barrier installed in the first year, since it was observed that, after a year, there was already a considerable amount of dust and other debris over it that would negatively interfere with its reflective and emissive properties (Fig. 28).

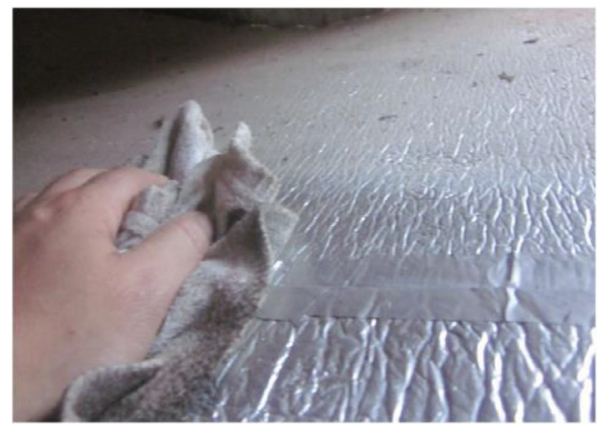

Fig. 28. Dust had accumulated on the radiant barrier applied in the summer of the 1 st year.

In the third measurements phase, the mean value of the outdoor air temperature was $19.3^{\circ} \mathrm{C}$ and the maximum value was $27.9{ }^{\circ} \mathrm{C}$. The maximum solar irradiance on horizontal surface was $856 \mathrm{~W} / \mathrm{m}^{2}$. Table 5 shows the minimum, maximum and mean values of the temperature in the attics of the roofs and in the bedrooms

Fig. 29 shows the variation of temperatures throughout the third and final measurements phase.

As can be seen in Fig. 29, the application of the radiant barrier leads to a reduction in thermal amplitudes, especially in the attic of the eastern roof, in comparison to the attic of the western roof.

\section{Results analysis: CAPSOL simulation}

A previous validation of the model was performed using the measured values for the presented case study, and a reasonable approximation of the values calculated through CAPSOL to the values measured experimentally was obtained [19].

In order to proceed with a parametric study for Maia climatic conditions, since there were no climate files in the database of the program for this location, three climate files were produced for Maia (outdoor air temperature, global horizontal solar irradiance and diffuse solar irradiance) with hourly data from a reference year (TRY) whose source was the data base of SOLTERM software [20] used in Portugal to carry out the performance analysis and design of active solar systems.

From the various simulations carried out in a wider study, the results of two situations that were compared in order to conclude on the advantages of the use of radiant barriers in terms of summer comfort are presented. The simulations were held for the first seven days of August and they concerned the eastern roof of the same building presented above. 
Table 5

Temperature values $\left({ }^{\circ} \mathrm{C}\right)$, in 2 nd year summer (third phase).

\begin{tabular}{llllll}
\hline & \multicolumn{2}{l}{ Western sector } & & \multicolumn{2}{l}{ Eastern sector } \\
\cline { 2 - 3 } \cline { 5 - 6 } & Roof attic without RB & Bedroom without RB & & Roof attic with RB & Bedroom with RB \\
\hline Minimum values & 11.0 & 21.0 & 12.6 & 19.8 \\
Maximum values & 34.0 & 23.2 & 27.1 & 22.9 \\
Mean values & 20.7 & 22.3 & 21.1 & 21.4 \\
\hline
\end{tabular}

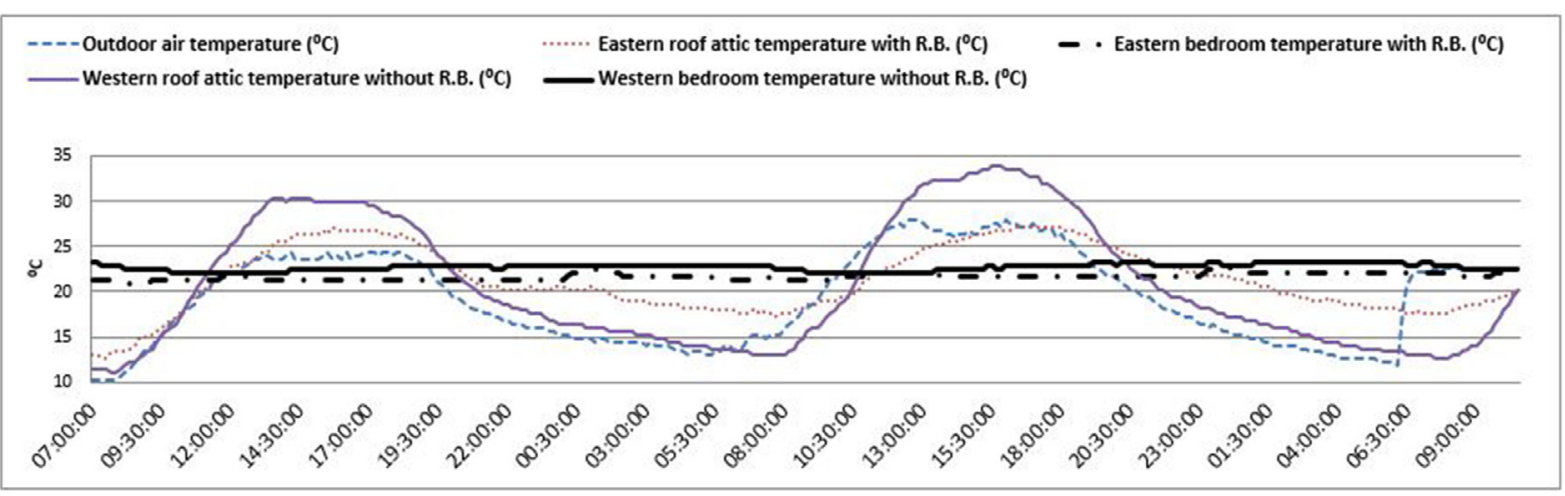

Fig. 29. Variation of temperature of the outdoor air, the eastern and western roof attics and the bedrooms, in the third phase of measurements

Table 6

Mean and maximum values of temperature $\left({ }^{\circ} \mathrm{C}\right)$ in the five thermal zones.

\begin{tabular}{lll}
\hline Thermal zone & Mean temperature & Maximum temperature \\
\hline Outdoors & 19.7 & 30.1 \\
Air space between the tiles and the RB & 25.0 & 44.2 \\
Roof attic & 23.0 & 29.7 \\
Bedroom & 22.6 & 24.1 \\
The rest of the indoor space & 20.0 & 20.0 \\
\hline
\end{tabular}

Table 7

Mean and maximum values of surface temperature $\left({ }^{\circ} \mathrm{C}\right)$.

\begin{tabular}{lll}
\hline Surface & Mean value & Maximum value \\
\hline Upper surface of the ceramic tiles & 25.3 & 49.0 \\
Lower surface of the ceramic tiles & 25.3 & 48.6 \\
Upper surface of the radiant barrier & 24.1 & 37.8 \\
Lower surface of the radiant barrier & 23.9 & 36.1 \\
Upper surface of the floor slab of the roof attic & 23.0 & 29.2 \\
Lower surface of the floor slab of the roof attic & 22.5 & 23.4 \\
\hline
\end{tabular}

The first situation was the application of a radiant barrier that integrates highly polished aluminum films, with an emissivity value of 0.06 , both immediately above the roof slab and under the roof tiles (creating a $4 \mathrm{~cm}$ thick air space ventilated at three air changes per hour).

For this model five thermal zones were considered as follows:

- Outdoors;

- $4 \mathrm{~cm}$ air space between the tiles and the radiant barrier;

- Roof attic;

- Bedroom;

- The rest of indoor space (which was assumed to be in the summer period at a constant temperature of $20^{\circ} \mathrm{C}$, a value very close to the mean value of outdoor air temperature in that period).

It was also considered that all bedroom windows had the inner aluminum shutters always fully closed, in order to minimize the influence of the incidence of direct solar radiation that could enter through the glazing, a situation that existed in the field tests.

Fig. 30 shows the variation of the outdoor air temperatures and of the rest of the indoor space as well as the operative temperatures in the bedroom, in the air space under the roof tiles and in the roof attic.
Table 6 presents the corresponding values of the mean and maximum temperatures reached in the five thermal zones in the period under analysis.

In Table 7, the mean and maximum values of the surface temperatures of the roof tile, the radiant barrier and the floor slab of the attic, both on its lower and upper surfaces, are presented.

In what regards heat flux by radiation between the roof attic and its floor slab, for the considered period, this has a mean value of $0.1 \mathrm{~W} / \mathrm{m}^{2}$ upward and a maximum value of $1.3 \mathrm{~W} / \mathrm{m}^{2}$ downward.

The second simulated situation corresponded to the removal of all radiant barriers (from the roof slab and from the roof tiles) from the previous scenario in order to compare the two situations. Thus, the thermal model was reduced to four thermal zones.

Fig. 31 shows the graph corresponding to the second simulated situation that shows the variation of the outdoor air temperature and of the rest of the indoor space, as well as the operative temperatures of the bedroom and of the roof attic.

Table 8 presents the corresponding mean and maximum values of the temperatures of the four thermal zones in the period under analysis.

In Table 9, the mean and maximum values of the surface temperatures of the roof tiles and the floor slab of the attic, both on the lower and upper surfaces, are presented. 


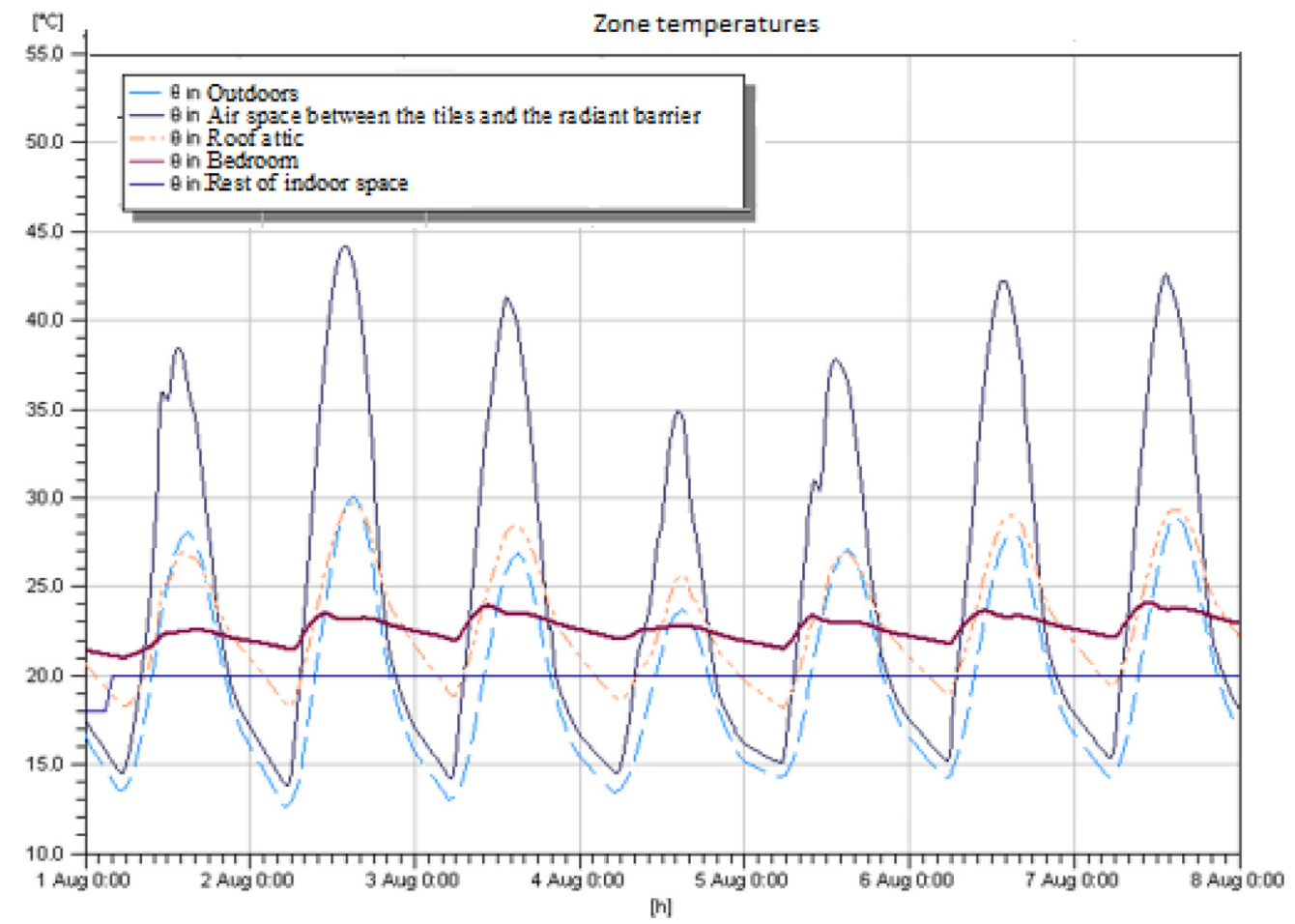

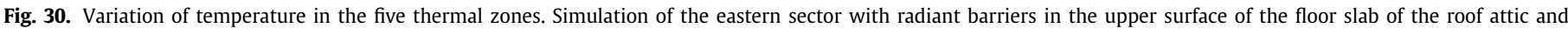
on the lower surface of the roof slopes.

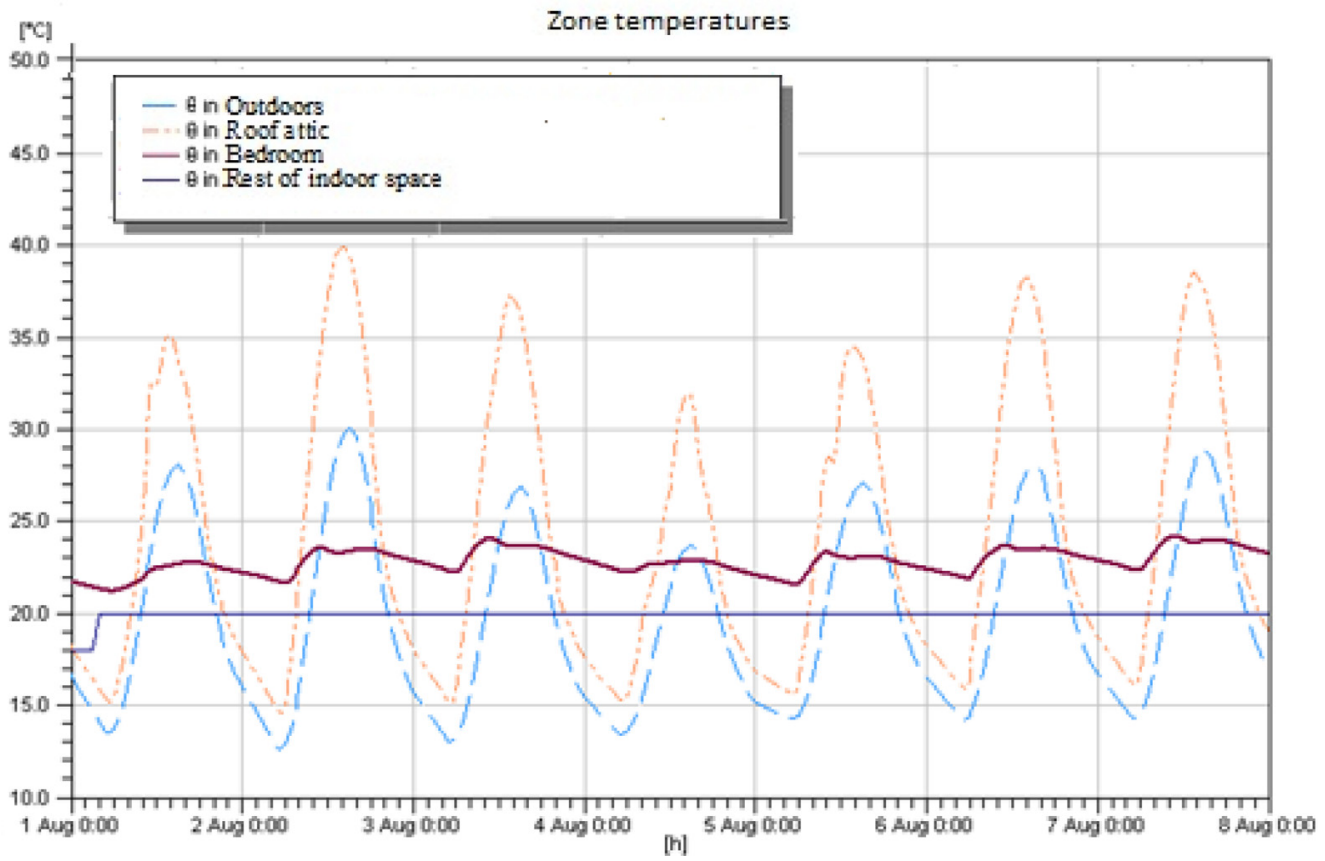

Fig. 31. Variation of temperature in the four thermal zones. Simulation of the eastern sector with no radiant barriers.

Table 8

Mean and maximum values of temperature in the four thermal zones $\left({ }^{\circ} \mathrm{C}\right)$.

\begin{tabular}{lll}
\hline Thermal zone & Mean temperature & Maximum temperature \\
\hline Outdoors & 19.7 & 30.1 \\
Roof attic & 24.2 & 39.9 \\
Bedroom & 22.8 & 24.2 \\
The rest of the indoor space & 20.0 & 20.0 \\
\hline
\end{tabular}

In what regards heat flux by radiation between the roof attic and its floor slab, its mean value was $1.9 \mathrm{~W} / \mathrm{m}^{2}$ and the maximum value was $13.0 \mathrm{~W} / \mathrm{m}^{2}$, both downward.

From the comparison of the two situations, it can be concluded that the impact of radiant barriers on the room operative temperature is minimal, resulting only in a decrease of $0.2^{\circ} \mathrm{C}$ in the mean value and of $0.1{ }^{\circ} \mathrm{C}$ in the maximum value. However, with regard to the temperature of the roof attic, the difference is much more significant, with a mean temperature decrease of $1.2^{\circ} \mathrm{C}$ and a maximum of about $10.0^{\circ} \mathrm{C}$. The mean surface temperature of the bedroom ceiling decreased by $0.3{ }^{\circ} \mathrm{C}$ and its maximum value by $0.6{ }^{\circ} \mathrm{C}$. 
Table 9

Mean and maximum values of surface temperature $\left({ }^{\circ} \mathrm{C}\right)$, with no radiant barriers.

\begin{tabular}{lll}
\hline Surface & Mean value & Maximum value \\
\hline Upper surface of the ceramic tiles & 25.1 & 48.0 \\
Lower surface of the ceramic tiles & 25.0 & 47.3 \\
Upper surface of the floor slab of the roof attic & 24.2 & 38.4 \\
Lower surface of the floor slab of the roof attic & 22.8 & 24.0 \\
\hline
\end{tabular}

Table 10

Mean and maximum values of temperature $\left({ }^{\circ} \mathrm{C}\right)$ in the thermal zones, when there are no rock wool blankets at the floor slab of the roof attic.

\begin{tabular}{llllll}
\hline \multirow{2}{*}{ Zone } & \multicolumn{2}{l}{ Mean temperature } & & \multicolumn{2}{c}{ Maximum temperature } \\
\cline { 5 - 6 } & With RB & Without RB & & With RB & Without RB \\
\hline Outdoors & 19.7 & 19.7 & & 30.1 & 30.1 \\
Air space between tiles and the RB & 24.9 & - & & 43.6 & - \\
Roof attic & 22.6 & 23.8 & & 27.2 & 34.4 \\
Bedroom & 22.6 & 23.1 & & 24.0 & 24.9 \\
Rest of the indoor space & 20.0 & 20.0 & & 20.0 & 20.0 \\
\hline
\end{tabular}

Table 11

Mean and maximum values of surface temperatures $\left({ }^{\circ} \mathrm{C}\right)$, when there are no rock wool blankets at the floor slab of the roof attic.

\begin{tabular}{llllll}
\hline \multirow{2}{*}{ Surface } & \multicolumn{2}{l}{ Mean value } & & \multicolumn{2}{l}{ Maximum value } \\
\cline { 2 - 3 } \cline { 5 - 6 } \cline { 5 - 6 } & With RB & Without RB & & With RB & Without RB \\
\hline Upper surface of the ceramic tiles & 25.3 & 25.1 & 48.9 & 46.8 \\
Lower surface of the ceramic tiles & 25.3 & 24.9 & 48.4 & 45.6 \\
Upper surface of the radiant barrier & 23.9 & - & 36.1 & - \\
Lower surface of the radiant barrier & 23.6 & - & 33.9 & - \\
Upper surface of the floor slab of the roof attic & 22.6 & 23.6 & 24.9 & 28.3 \\
Lower surface of the floor slab of the roof attic & 22.5 & 23.3 & & 23.6 & 25.9 \\
\hline
\end{tabular}

Finally, as for the maximum value of the heat flux by radiation between the attic and its floor slab, the application of a radiant barrier allowed a decrease of $11.8 \mathrm{~W} / \mathrm{m}^{2}$.

Since there was a thermal insulation of rock wool on the slab of the attic in the first two simulations, it was decided to simulate a third scenario in which the exclusive influence of the radiant barrier could be identified by removing the original rock wool insulation. Thus, two new situations with and without radiant barrier were compared, assuming the absence of rock wool in any of them.

Table 10 shows the mean and maximum values of the temperatures reached in the various thermal zones, for the scenarios without blankets of rock wool.

In Table 11, the mean and maximum values of the surface temperatures of the roof tiles, the radiant barrier and the floor slab of the attic are presented, both in their lower and upper surfaces.

From the comparison between the presented situations in which the radiant barrier is the only existing insulation, it can be observed that the impact of the radiant barrier on the room operative temperature is slightly higher, resulting in a decrease of $0.5{ }^{\circ} \mathrm{C}$ in the mean value and $0.9{ }^{\circ} \mathrm{C}$ in the maximum value. Regarding the maximum temperature of the roof slope the difference is less pronounced than before when the rock wool was found. With the exclusive use of the radiant barrier the maximum surface temperature of the bedroom ceiling suffered a more significant decrease, being of $0.8{ }^{\circ} \mathrm{C}$ in the mean value and of $2.3{ }^{\circ} \mathrm{C}$ in the maximum value. Finally, as to the maximum value of the heat flux by radiation between the attic and its floor slab the application of a radiant barrier caused a decrease of $40.7 \mathrm{~W} / \mathrm{m}^{2}$.

The examples of simulations presented show the same trend already seen in the results of measurements performed, in the sense that the use of radiant barriers, under the roof slopes and on the attic floor slab, is advantageous in particular with regard to the decrease, in the hottest summer days, of the maximum temperatures of the roof attic and of the descending heat flow by radiation to the attic floor slab.

To improve the results discussion it is important refer other studies and know the results obtained. Lee et al. [21] made an exhaustive review of the several studies on radiant barrier and reflective insulation, and reached the following conclusions that agree with the present study carried out in Portugal:

- Generally data obtained from various research works, showed that the use of radiant barrier is particularly effective in reducing heat flux in summer;

- Taking into account all studies, the percentage of peak ceiling heat flux reductions in relative to the house without this radiant barriers systems ranged from $26 \%$ to $50 \%$ during summer;

- With this reduction of heat flux, peak attic air temperature was, in relative to the house without this radiant barriers systems, lower by $4{ }^{\circ} \mathrm{C}$ to $10{ }^{\circ} \mathrm{C}$.

\section{Conclusions}

The main conclusions drawn from the results presented above are the following:

- The use of radiant barriers can be advantageous mainly to attenuate the maximum temperatures reached inside the buildings, as well as the heat flow transmitted through the roofs, in the days of extreme temperatures and with more intense solar radiation;

- However, for the TRB solution, the attenuation of the heat peaks inside the roof attic is substantially more evident than in the rooms that underlie it;

- The advantage of the use of radiant barriers, in terms of temperature attenuation in average daily terms, is not so evident for mild climates (as in the North of Portugal), since these av- 
erages always enter the night period. Obviously, in terms of diurnal daily averages, the difference is already more significant;

- Some advantages were observed in the application of radiant barriers, in addition to the floor slab of the attic, also in the slopes of the roof underneath the tiles, because the maximum temperature reached in the attic, thus isolated, is significantly lower. In addition, this solution allows to greatly reduce the amount of dust that accumulates above the horizontal radiant barrier, since most of the dust comes through the tiles and the slits between them. This solution of placement of the radiant barrier under the slopes of the roof will influence the degree of ventilation of the attic. In order to ensure such ventilation, it is absolutely necessary to develop complementary measures;

- The simulations carried out indicate, in fact, that the greatest advantage of the use of radiant barriers in the roof is mainly to contribute to the control of the temperature of the attic, avoiding its overheating.

\section{Declarations of interest}

\section{None}

\section{References}

[1] F. Vittorino, N. Sato, M. Akutsu, Thermal performance of reflective insulation materials and radiant barriers applied in roofs (in Portuguese), in: VII Encontro Nacional sobre Conforto no Ambiente Construído (VII National Meeting on Comfort in the Built Environment) (ENCAC) - COTEDI, Curitiba-PR-Brazil, 2003, pp. 1277-1284.

[2] ASTM - American Society for Testing and Materials, Practice for installation and use of reflective insulation in building constructions, ASTM C 727 - 01, West Conshohocken, Pennsylvania, USA, 2007.

[3] CEN - Comité Européen de Normalisation. EN-ISO 6946 - Building components and building elements - thermal resistance and thermal transmittance - calculation method. European Standard, Brussels, 2017.

[4] M. Al-Homoud, Performance characteristics and practical applications of common building thermal insulation materials, Elsevier, Building and Environment Journal 40 (2004) 353-366.

[5] L. Matias, Evaluation of Thermal Performance of Reflective Protections Applied to Pitched Roofs (in Portuguese) Master Thesis in Physical Engineering, LNEC - Laboratório Nacional de Engenharia Civil (Portuguese National Laboratory of Civil Engineering), Lisbon, Portugal, 2001.
[6] National Physical Laboratory, IR Hemispherical Spectral Reflectance and Total Emittance, Teddington Middlesex, U.K, 2001 Reference E01070229/1.

[7] Unicamp - Universidade Estadual de Campinas, Brasil - Faculdade de Engenharia Mecânica (State University of Campinas, Brazil - Faculty of Mechanical Engineering) [Online]. Available at http://www.fem.unicamp.br/ vidalong/projleite. html. [accessed on 24/10/2017].

[8] Portal Metálicas (Methalics Portal) [Online]. Available at http://www.metalica. com.br/ecotelhado [accessed on 24/10/2017].

[9] Instituto para o Desenvolvimento da Habitação Ecológica do Brasil (Institute for the Development of Ecological Housing in Brazil) [Online]. Available at http: //www.idhea.com.br/ecotelha_tubo.asp. [accessed on 2/4/2012].

[10] M. Medina, M. Frempong, Evaluation of ceiling heat fluxes in residential buildings with attic radiant barriers in prevalent climates across the United States, in: Proceedings of Building Integration Solutions, Architectural Engineering 2003 Conference, U.S.A, 2003.

[11] P. Incropera, D. DeWitt, Fundamentals of Heat and Mass Transfer (Portuguese edition), sixth ed., Livros Técnicos e Científicos, Rio de Janeiro, Brazil, 2008.

[12] NASA_IPAC -Infrared Processing and Analysis Center. [Online]. Available at http://coolcosmos.ipac.caltech.edu/cosmic_classroom/classroom_activities/ herschel_experiment.html. [accessed on 22/03/2017].

[13] J. Borges, Cosmology and Cosmic Radiation as a Motivating Element for High School Education (in Portuguese) Master Thesis, Teaching of Astronomy, Porto, Portugal, 2008.

[14] Physibel. Capsol 4.0, Computer Program to Calculate Multizone Transient Heat Transfer, Physibel document M-CP-A-E07, Maldegem, Belgium, 2002.

[15] A. Rodrigues, A. Piedade, A. Braga, Thermal Behavior of Buildings (in Portuguese), Orion Editions, Amadora, Portugal, 2009.

[16] University of Minho, Portugal. [Online]. Available at http://online.uminho. pt/pessoas/lanceros/Material\%20L-EGI/Material\%20-\%20LEGI/-Termo-din\%C3\% A2mica-I.pdf. [accessed on 24/04/2012].

[17] CEN - Comité Européen de Normalisation. EN-ISO 13789 -thermal performance of buildings. transmission and ventilation heat transfer coefficients - calculation method, European Standard, Brussels, 2017.

[18] W. Janna, Engineering Heat Transfer, second ed., CRC Press, USA, 2000.

[19] M. Ferreira, Reflective Thermal Insulation Materials with Low Emissivity - Performance, Applications, Optimization and Comparison with Other Insulation Materials (in Portuguese) PhD Thesis in Civil Engineering, Faculty of Engineering of the University of Porto, Porto, Portugal, 2017.

[20] Laboratório Nacional de Energia e Geologia (Portuguese National Laboratory of Energy and Geology). SOLTERM - Analysis of Solar Systems Performance (in Portuguese). [Online]. Available at www.lneg.pt/iedt/projectos/370/. [accessed on $01 / 09 / 2016]$.

[21] S. Lee, L. Chin, E. Salleh, Reflective thermal insulation systems in building: a review on radiant barrier and reflective insulation, J. Renew. Sustainable Energy Rev. 65 (2016) 643-661. 